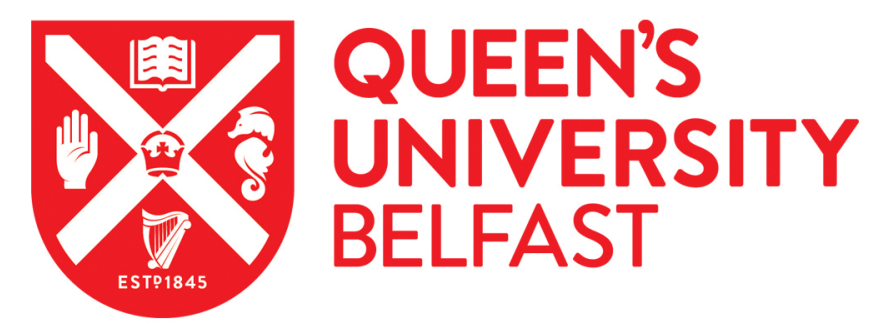

\title{
Photocontrolled Release of Doxorubicin Conjugated through a Thioacetal Photocage in Folate-Targeted Nanodelivery Systems
}

Wong, P. T., Tang, S., Cannon, J., Chen, D., Sun, R., Lee, J., Phan, J., Tao, K., Sun, K., Chen, B., Baker, J. R., \& Choi, S. K. (2017). Photocontrolled Release of Doxorubicin Conjugated through a Thioacetal Photocage in Folate-Targeted Nanodelivery Systems. Bioconjugate Chemistry, 28(12), 3016-3028.

https://doi.org/10.1021/acs.bioconjchem.7b00614

Published in:

Bioconjugate Chemistry

Document Version:

Peer reviewed version

Queen's University Belfast - Research Portal:

Link to publication record in Queen's University Belfast Research Portal

Publisher rights

Copyright $\odot 2017$ American Chemical Society. This work is made available online in accordance with the publisher's policies. Please refer to any applicable terms of use of the publisher.

\section{General rights}

Copyright for the publications made accessible via the Queen's University Belfast Research Portal is retained by the author(s) and / or other copyright owners and it is a condition of accessing these publications that users recognise and abide by the legal requirements associated with these rights.

Take down policy

The Research Portal is Queen's institutional repository that provides access to Queen's research output. Every effort has been made to ensure that content in the Research Portal does not infringe any person's rights, or applicable UK laws. If you discover content in the Research Portal that you believe breaches copyright or violates any law, please contact openaccess@qub.ac.uk. 


\section{Photocontrolled Release of Doxorubicin Conjugated through a Thioacetal Photocage in Folate-Targeted Nanodelivery Systems}

Pamela T. Wong, ${ }^{\dagger}{ }^{\dagger}$ Shengzhuang Tang, ${ }^{\dagger}+{ }^{\dagger}$ Jayme Cannon, ${ }^{\dagger},+$ Dexin Chen, ${ }^{\S}$ Rachel Sun,,${ }^{\dagger}$ Jennifer Lee, ${ }^{\dagger}$ James Phan, ${ }^{\dagger}$ Ke Tao, ${ }^{*}{ }^{\S}$ Kang Sun,,${ }^{*}$ Biqiong Chen, ${ }^{\Downarrow}$ James R. Baker, Jr., ${ }^{\dagger}{ }^{\ddagger}$ and Seok Ki Choi $^{*} \uparrow, *$

${ }^{\dagger}$ Michigan Nanotechnology Institute for Medicine and Biological Sciences, ${ }^{\ddagger}$ Department of Internal Medicine, University of Michigan Medical School, Ann Arbor, Michigan 48109, United States

${ }^{\S}$ State Key Laboratory of Metal Matrix Composites, School of Materials Science and Engineering, Shanghai Jiao Tong University, Shanghai 200240, People’s Republic of China

"School of Mechanical and Aerospace Engineering, Queen's University Belfast, Stranmillis Road, Belfast BT9 5AH, United Kingdom

*To whom correspondence should be addressed,

E-mail: ktao@sjtu.edu.cn

E-mail: ksun@sjtu.edu.cn

E-mail: skchoi@umich.edu 


\begin{abstract}
Despite their proven ability for precise and targeted release, nanoplatform systems for photocontrolled delivery often face formidable synthetic challenges, in part, due to the paucity of advanced linker strategies. Here we report on a novel linker strategy using a thioacetal orthonitrobenzaldehyde (TNB) cage, demonstrating its application for delivery of doxorubicin (Dox) in two nanoscale systems. This photocleavable linker, $\mathrm{TNB}(\mathrm{OH})$, which presents two identical arms, each terminated with a hydroxyl functionality, was prepared in a single step from 6nitroveratraldehyde. $\mathrm{TNB}(\mathrm{OH})$ was used to crosslink Dox to a folate receptor (FAR)-targeting poly(amidoamine) dendrimer conjugate $\mathrm{G} 5(\mathrm{FA})_{\mathrm{n}=5.4}(\mathrm{Dox})_{\mathrm{m}=5.1}$, and also used to prepare an upconversion nanocrystal (UCN) conjugate, UCN-PPIX@(Dox)(G5FA), a larger core/shell nanostructure. In this core/shell nanostructure, the UCN core emits UV and visible light luminescence upon near IR (NIR) excitation, allowing for the photocleavage of the TNB linker as well as the photostimulation of protoporphyrin IX (PPIX) coupled as a cytotoxic photosensitizer. Drug release experiments performed in aqueous solutions with long wavelength UVA light showed that Dox release occurred rapidly from its TNB linked form or from its dendrimer conjugated form with comparable decay kinetics. Cellular toxicity studies in FARoverexpressing KB carcinoma cells demonstrated that each nanoconjugate lacked intrinsic cytotoxicity until exposed to UVA or NIR $(980 \mathrm{~nm}$ ) (for the UCN nanoconjugate), which resulted in induction of potent cytotoxicity. In summary, this new TNB strategy offers synthetic convenience in drug conjugation chemistry with the ability for temporal control of drug activation at the delivery site.
\end{abstract}




\section{Introduction}

Nanotechnology has played a central role in the rapid advances made recently in the development of nanometer-scale constructs as targeted, image-guided and controlled delivery platforms. ${ }^{1-3}$ These nanoconstructs have been broadly explored as delivery systems for anticancer agents, $^{4-7}$ antibiotics, ${ }^{8-12}$ siRNAs ${ }^{13,14}$ and therapeutic genes. ${ }^{15,} 16$ They offer a variety of physicochemical strategies for payload conjugation that are tailored to specific diseases for detection, imaging, and treatment purposes. ${ }^{2,17,18}$ However, the effectiveness of each system varies significantly as dictated by several design factors. The targeting efficiencies of these nanoparticle (NP) constructs are determined by a combination of their physicochemical properties including NP type, size and surface chemistry ${ }^{19,20}$ as well as by the specificity, affinity, and multivalency of the ligands conjugated to the NPs which bind to specific disease biomarkers. $^{21-25}$ Furthermore, the method of drug conjugation and the design of the linker play a critical role in facilitating payload release and for controlling the release such that it occurs precisely in the targeted cells and tissues. ${ }^{4,11,16,26-28}$ Here we report a new approach for NP-drug conjugation based on a thioacetal photocleavable linker, and discuss its application and efficiency for light-controlled doxorubicin (Dox) release in two folate receptor (FAR)-targeted delivery systems.

Linkers are all designed with the purpose of tethering therapeutic molecules to a NP carrier, but they vary drastically in the types of conjugation chemistry and therefore in the mechanisms they utilize for drug release. ${ }^{26}$ Most of the linker chemistries currently developed for tumortargeted nanoconjugates rely on stable but conditionally-cleavable covalent bonds such as disulfide, ${ }^{29}$ ester $^{30}$ amide (cis-aconityl ${ }^{31}$ ), oxime, ${ }^{32}$ and peptide (PVGLIG ${ }^{33}$ ). Each of these is designed to be cleaved selectively in response to an endogenous factor and/or under a 
pathologically associated condition such as through a thiol/disulfide exchange (glutathione $\left.[\mathrm{GSH}]_{\text {cellular }}=2-10 \mathrm{mM}\right),{ }^{29}$ low $\mathrm{pH}(5.5-6.5$ in endosomes, lysosomes $)$, overexpressed proteases (matrix metalloproteinases), ${ }^{33}, 34$ hypoxia, ${ }^{35}$ and the presence of various tumor biomarkers. ${ }^{26}$ In addition, other distinct linker types have also been developed for active control of payload release with an exogenous stimulus through photodynamic, ${ }^{36}$ photothermal, ${ }^{37,38}$ sonodynamic, ${ }^{39}$ or light activation. ${ }^{5,6,28,40}$ Among such exogenous stimuli, use of light offers unique advantages due to the availability of various light sources, the higher degree of spatial resolution, ${ }^{8,16,41}$ and proven clinical utility. ${ }^{42}$ Long wavelength UVA light $(315-400 \mathrm{~nm})$ has been effectively used for spatiotemporal control of compound release in vitro and in vivo in many fields including optogenetics ${ }^{43}$ and drug delivery, ${ }^{16,28}$ while visible light $(400-700 \mathrm{~nm})$ has been used in clinics for photodynamic therapy (PDT). ${ }^{42}$
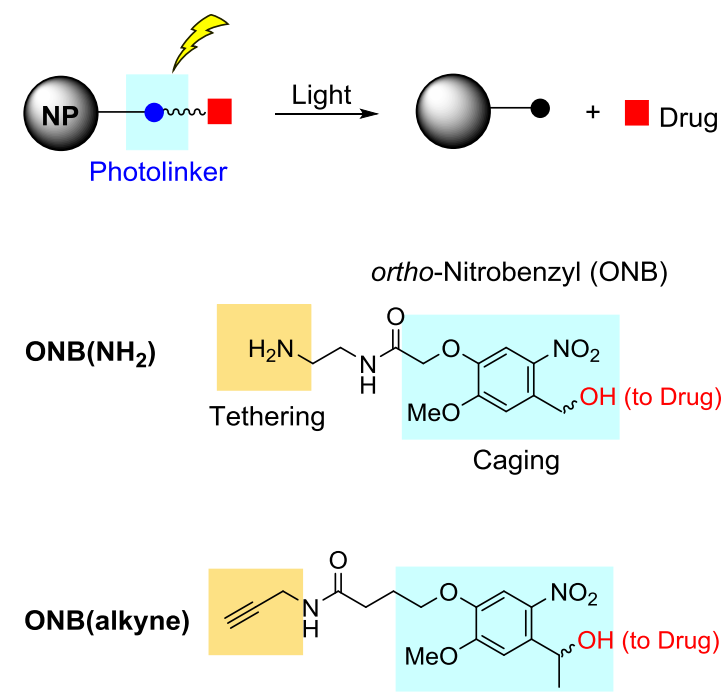

Figure 1. ortho-Nitrobenzyl (ONB) photocleavable linkers used for light-controlled drug release in nanoparticle (NP) delivery systems. Two ONB linkers are illustrated, each terminated with an amine $^{5}$ or alkyne ${ }^{6}$ functionality for NP tethering through amide or azide-alkyne click conjugation chemistry. 
Linker chemistry developed for photocontrolled delivery is based largely on the concept of photocaging ${ }^{44}$ which enables the temporary inactivation of a molecule using a photocleavable group such that upon light irradiation, the active form of its caged molecule is irreversibly released (Figure 1). Many delivery systems have been successfully designed with this concept, in particular, utilizing long UVA-cleavable linkers consisting of ortho-nitrobenzyl (ONB) ${ }^{4-6,40,41}$ and coumarin. ${ }^{43}, 45$ These linkers have been applied in the controlled activation or release of payloads including 5-fluorouracil (5-FU), ${ }^{4}$ methotrexate, ${ }^{46}$ doxorubicin, ${ }^{5,} \quad 6, \quad 40, \quad 47,48$ ciprofloxacin, ${ }^{11}$ camptothecin, ${ }^{49}$ chlorambucil ${ }^{27}$ folate, ${ }^{41}$ and Alexa fluor $488 .{ }^{50}$ However, despite their high utility for precise control and broad payload applicability, the accessibility to such ONB or coumarin linkers is often limited due to the synthetic challenges that are faced, as each linker requires an additional tethering functionality to be used as a chemical handle for NP crosslinking. For example, the use of $\mathrm{ONB}$ linkers such as $\mathrm{ONB}\left(\mathrm{NH}_{2}\right)$ as we previously reported ${ }^{5}$ requires a total of seven divergent steps to get to the state where it is fully functionalized with an amine or alkyne unit for NP tethering through amide ${ }^{5,40}$ or azide-alkyne click $^{6}$ conjugation chemistry (Figure 1).

With a practical perspective, to address these synthetic challenges in photocaging technologies, we have been interested in thioacetal ortho-nitrobenzaldehyde (TNB) ${ }^{48}$ as a new type of photolinker (Figure 2). As reported recently from our laboratories, ${ }^{48}$ each TNB linker (1 and 2) has a photocaging group flanked by two identical arms. Because of their symmetry, each hydroxyl or carboxylic acid terminus can equally engage in either drug caging or NP tethering without incurring regioisomeric issues. Use of these TNB linkers offers synthetic convenience and large scale availability because of their synthesis from commercially available 6nitrovertraldehyde in one step. The thioacetal linkage that constitutes the core of TNB linkers 1 
and 2 displays rapid cleavage kinetics with quantum efficiencies $(\Phi=0.19-0.2)^{48}$ as effective as comparable ONB linkers $(\Phi=0.01-0.7) .{ }^{44}$ Both TNB and ONB share certain similarities in the initial step of the mechanism of cleavage which involves the generation of an aci-Nitro form in response to UV light (Figure 2). ${ }^{48}$ However, they show differences in subsequent fragmentation mechanisms and the distribution of release products as the TNB cleavage results in concomitant release of two species, proposed to be Dox(thiol) and Dox(thioester).
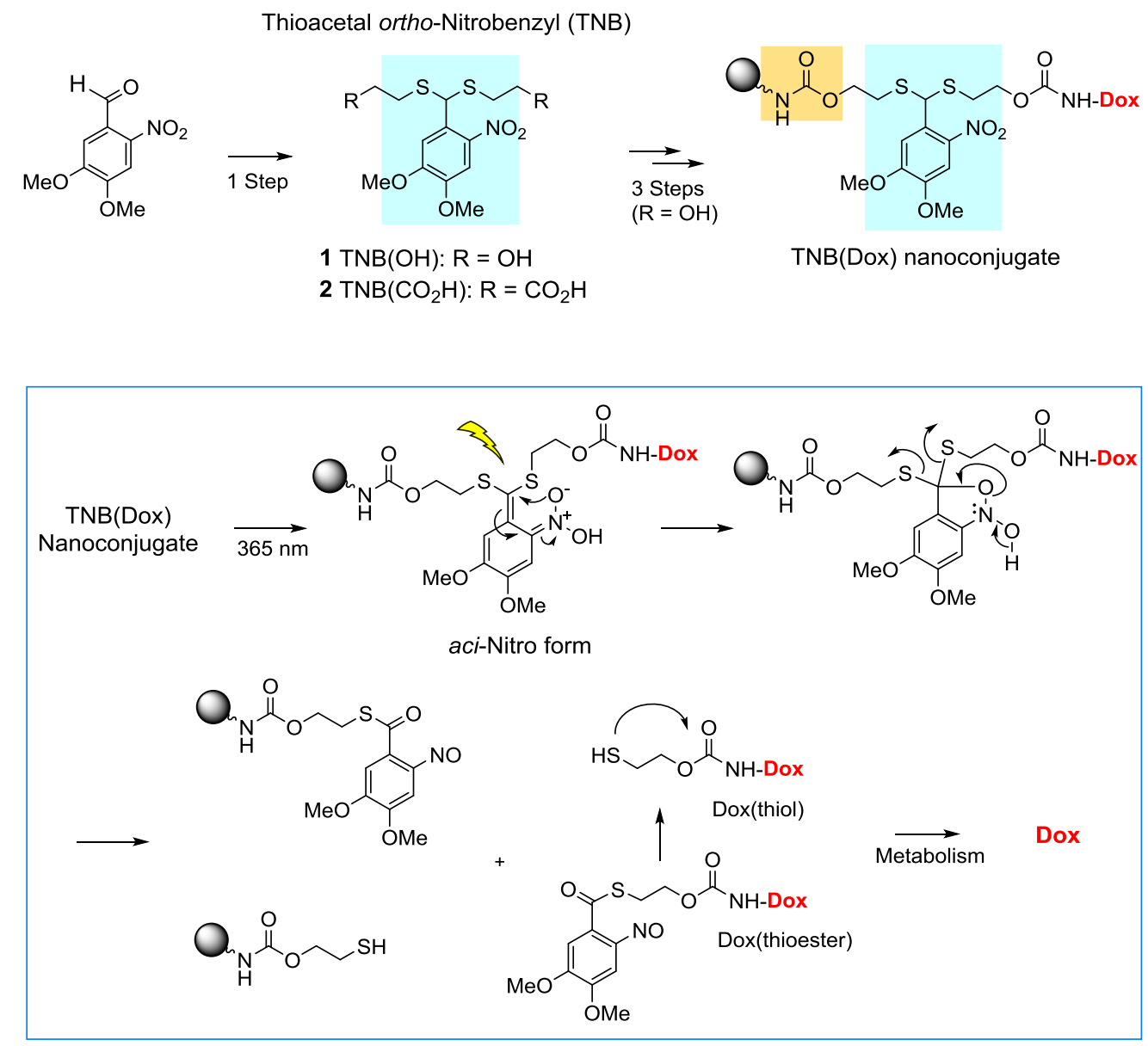

Figure 2. A dual-arm linker strategy based on thioacetal ortho-nitrobenzaldehyde (TNB) ${ }^{48}$ and a proposed mechanism of drug release via a TNB cleavage triggered by long wavelength UVA $(365 \mathrm{~nm})$. 
Our present study aims to evaluate the scope and validate the capability of TNB linkers in the targeted delivery of Dox, a clinical anticancer drug. It describes the methods involved in the synthesis of TNB-caged Dox conjugates and discusses the strategies developed for integrating these TNB-caged molecules into two FAR-targeting NP modules. The first NP module is based on a fifth generation (G5) poly(amidoamine) (PAMAM) dendrimer, ${ }^{3}$ G5(FA)(Dox), in which FA and TNB-Dox are conjugated to the terminal amines of the dendrimer branches. The second NP, UCN-PPIX@(Dox)(G5FA), is based on a core/shell upconversion nanocrystal (UCN) ${ }^{51}$ platform in which a UCN-PPIX (protoporphyrin IX) ${ }^{36}$ core is covalently coated with both a targeting G5(FA) 6 dendrimer and a TNB-caged Dox drug on its shell surface as two separate entities. This UCN-PPIX nanostructure was employed because its UCN core offers the unique ability to upconvert near IR (NIR) radiation into UV-vis emission, ${ }^{36}$ which serves as an internal light source for imaging and inducing the cleavage of the TNB linker. In addition, the presence of the PPIX layer coupled as a photosensitizer on the UCN surface was shown to be effective for producing reactive oxygen species (ROS) which led to photo-modulated cytotoxicity. ${ }^{36}$

\section{Results and Discussion}

TNB-caged Doxorubicin. $1 \mathrm{TNB}(\mathrm{OH})$ was synthesized from 6-nitroveratraldehyde by its reaction with 2-mercaptoethanol in a one-pot synthesis catalyzed by $\mathrm{BF}_{3} \cdot \mathrm{Et}_{2} \mathrm{O}$ as reported previously (Scheme 1). ${ }^{48}$ Each hydroxyl group in $\mathbf{1}$ was then activated by treatment with 4nitrophenyl (4-NP) chloroformate to an amine-reactive form, bis(4-nitrophenyl) carbonate 3. Because of their symmetry, each arm in $\mathbf{3}$ is equally able to engage in a conjugation reaction, allowing attachment of the TNB to two different molecules in reactions performed in sequence, such as first conjugation of one arm with a drug molecule and then conjugation of the other arm to a nanocarrier. Thus, 3 reacted with Dox to produce 4 through a carbamate linkage while 
leaving the other carbonate intact to be used later for tethering to a UCN-PPIX carrier which presents amines on the surface. As an alternative approach, 3 was first conjugated with mono $N$ Boc protected ethylenediamine and subsequently with Dox, yielding $\mathbf{5}$. Its $N$-Boc group could be deprotected to produce a free primary amine for its amide conjugation with a carboxylic acidterminated PAMAM dendrimer.

The structural identity and homogeneity ( $\geq 95 \%)$ of each of the TNB-caged compounds 3-5 were fully established by ${ }^{1} \mathrm{H}$ NMR spectroscopy and ultraperformance liquid chromatography (UPLC) analysis (Figure S1, Supporting Information). Some of these compounds were further characterized by UV-vis spectrometry $\left(5: \lambda_{\max }=498 \mathrm{~nm}(\right.$ Dox $\left.), \varepsilon=7882.7 \mathrm{M}^{-1} \times \mathrm{cm}^{-1}\right) ; 355 \mathrm{~nm}$ (TNB), $\varepsilon=4575.4 \mathrm{M}^{-1} \times \mathrm{cm}^{-1}$ ) and by high resolution mass spectral data which confirmed an agreement between the calculated and experimental values $\left(m / z\right.$ calcd for $\mathrm{C}_{48} \mathrm{H}_{49} \mathrm{~N}_{3} \mathrm{NaO}_{22} \mathrm{~S}_{2}[4+$ $\mathrm{Na}]^{+}$1106.2141; found 1106.2134; calcd for $\mathrm{C}_{49} \mathrm{H}_{60} \mathrm{~N}_{4} \mathrm{NaO}_{21} \mathrm{~S}_{2}[\mathbf{5}+\mathrm{Na}]^{+}$1127.3089, found 1127.3072).

Scheme 1. Synthesis of a thioacetal ortho-nitrobenzaldehyde (TNB) photolinker and its doxorubicin conjugates $^{a}$ 

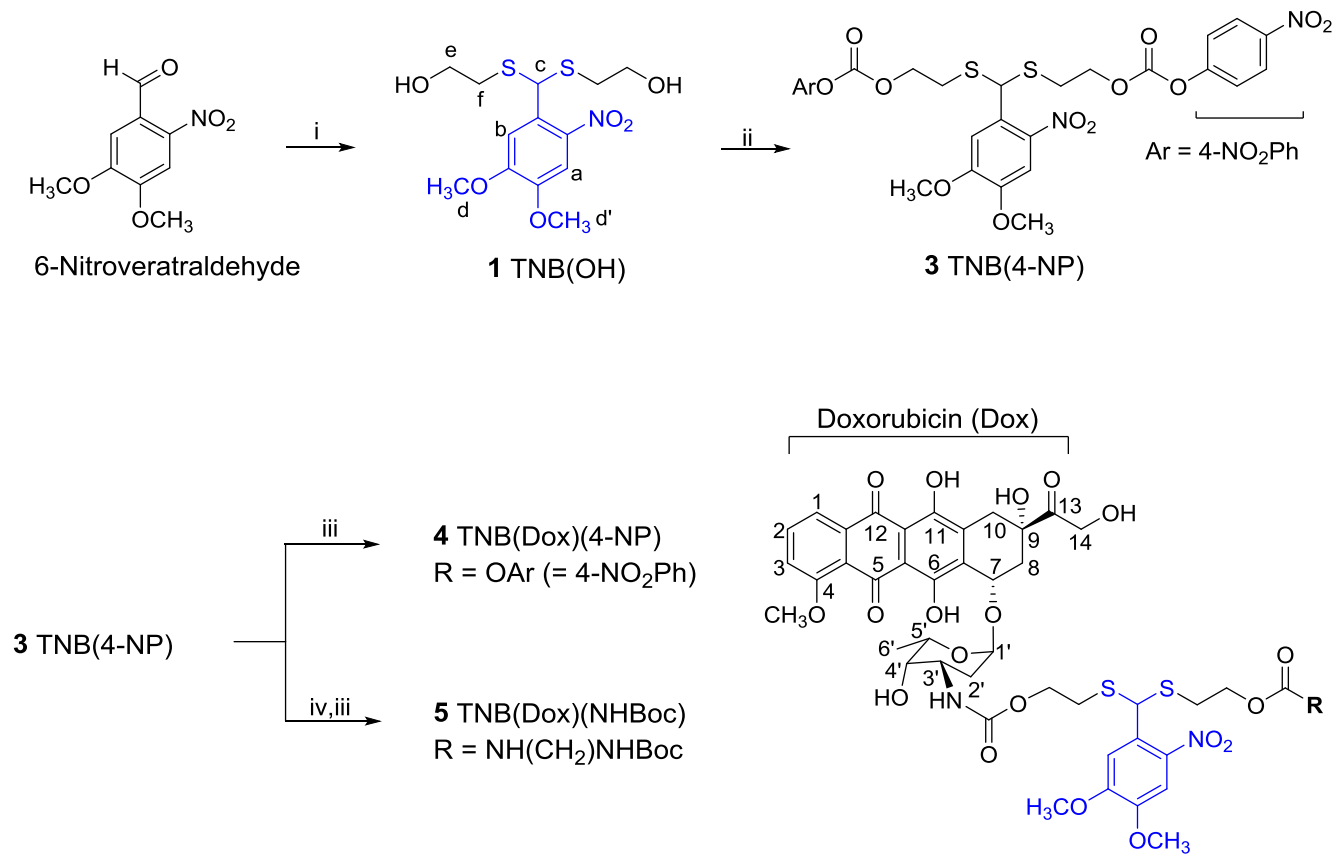

${ }^{a}$ Reagents and conditions: i) 2-Mercaptoethanol, $\mathrm{BF}_{3} \cdot \mathrm{Et}_{2} \mathrm{O}$, acetic acid, $0{ }^{\circ} \mathrm{C}$; ii) 4-Nitrophenyl chloroformate, $i$ - $\mathrm{Pr}_{2} \mathrm{NEt}, \mathrm{CH}_{2} \mathrm{Cl}_{2}$; iii) Doxorubicin-HCl, Et ${ }_{3} \mathrm{~N}$, DMF; iv) $N$-Boc ethylenediamine, $\mathrm{Et}_{3} \mathrm{~N}, \mathrm{CH}_{2} \mathrm{Cl}_{2}$.

Scheme 2. Synthesis of 9 G5(FA) $)_{n=5.4}(\text { Dox })_{m=5.1}$, a G5 PAMAM dendrimer conjugated with folate (FA) and TNB-caged Dox ${ }^{a}$ 

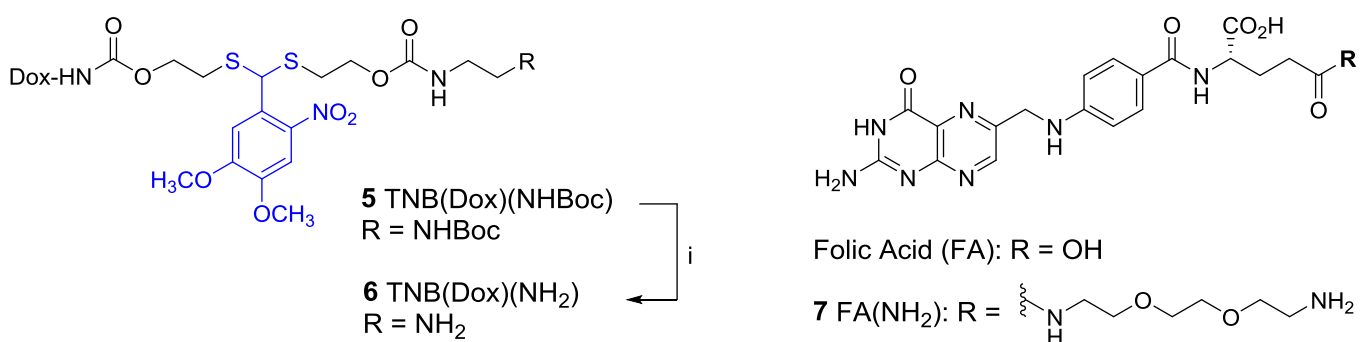

Folic Acid (FA): $\mathrm{R}=\mathrm{OH}$

$7 \mathrm{FA}\left(\mathrm{NH}_{2}\right): \mathrm{R}=$

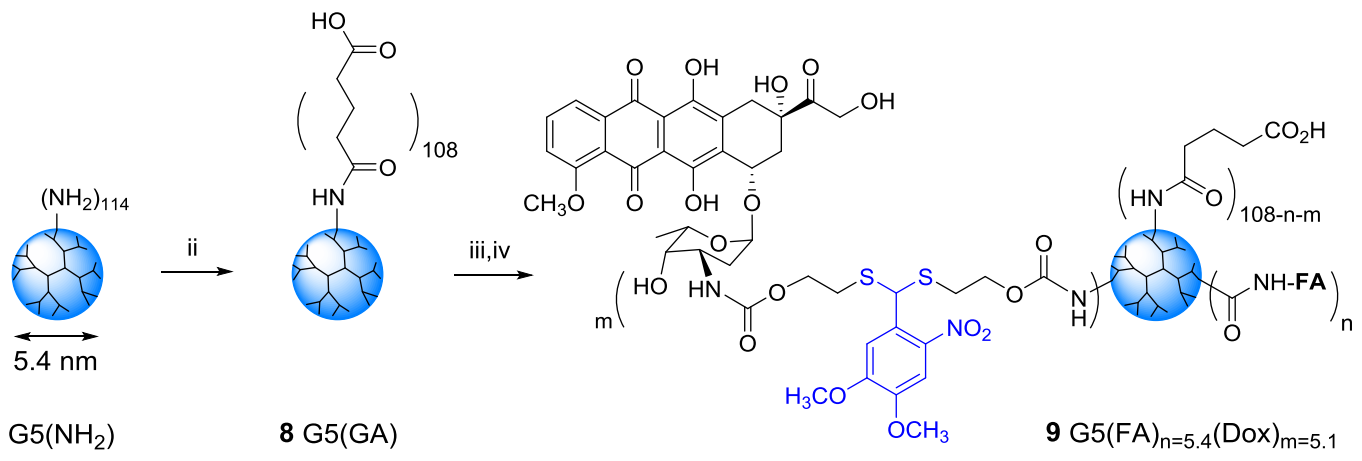

${ }^{a}$ Reagents and conditions: i) $\mathrm{CF}_{3} \mathrm{CO}_{2} \mathrm{H}, \mathrm{CH}_{2} \mathrm{Cl}_{2}$, room temp; ii) Glutaric anhydride (220 mol equiv), $\mathrm{Et}_{3} \mathrm{~N}, \mathrm{MeOH}$, room temp; iii) $N$-(3-Dimethylaminopropyl)- $N$ '-ethylcarbodiimide hydrochloride (EDC), $N$-hydroxysuccinimide (NHS), DMF, $36 \mathrm{~h}$, room temp; iv) 6 (10 mol equiv), 7 (20 mol equiv), $\mathrm{NEt}_{3}$, room temp.

TNB(Dox)-Conjugated PAMAM Dendrimer. In order to explore the applicability of TNB linker $\mathbf{1}$ in photocontrolled drug delivery, we selected a fifth generation (G5) poly(amidoamine) (PAMAM) dendrimer $\mathrm{G} 5\left(\mathrm{NH}_{2}\right)_{\mathrm{n}}(\mathrm{n}=$ theoretical number of peripheral amine branches $=128$, diameter $=5.4 \mathrm{~nm})^{3}$ as a nanoscale drug carrier. This class of PAMAM dendrimers displays excellent structural and functional features ideal for multivalent ligand presentation and drug delivery due to their large number of pre-organized peripheral branches, flexible shape, and hydrophobic internal cavities. ${ }^{3}$ As previously used for amide drug conjugation, ${ }^{5,11}$ a glutaric acid (GA)-terminated dendrimer $8\left(M_{\mathrm{r}}=40,200 \mathrm{gmol}^{-1}\right.$; polydispersity index $(\mathrm{PDI})=M_{\mathrm{w}} / M_{\mathrm{n}}$ $\sim 1.046)^{5}$ which was prepared by treatment of $\mathrm{G} 5\left(\mathrm{NH}_{2}\right)_{\mathrm{n}}=114$ with excess glutaric anhydride, served as a platform for conjugating $\operatorname{TNB}($ Dox). This dendrimer was preactivated at its 
peripheral carboxylic acids by treatment with $N$-(3-dimethylaminopropyl)- $N^{\prime}$-ethylcarbodiimide (EDC) $/ N$-hydroxysuccinimide (NHS), and was subsequently incubated with a mixture of $\mathbf{6}$ and $\mathbf{7}$, a folate $(\mathrm{FA})$ ligand $\left(K_{\mathrm{D}}=5.9 \times 10^{-6} \mathrm{M}\right.$; monovalent $\mathrm{FA}$ to folate binding protein $\left.{ }^{40}\right)$ to produce 9.

The dendrimer conjugate was purified through multiple cycles of exhaustive dialysis in a membrane tubing (MWCO $10 \mathrm{kDa}$ ), and its identity was characterized by standard methods including UV-vis spectrometry for the respective chromophores $\left(\lambda_{\max }=283 \& 355\right.$ for FA \& TNB; $497 \mathrm{~nm}$ for Dox), matrix assisted laser desorption ionization time-of-flight (MALDI-TOF) mass spectrometry $\left(M_{\mathrm{r}}=48,000 \mathrm{gmol}^{-1}\right)$, and UPLC for homogeneity ( $>95 \%$ polymer purity) (Figure S1, Supporting Information). The ligand $(n)$ or drug $(m)$ valencies indicated for 9 $\mathrm{G} 5(\mathrm{FA})_{n}(\text { Dox })_{m}$ refers to the number of FA or TNB(Dox) molecules attached to each dendrimer nanoparticle, determined on an average basis by a H NMR integration method in combination with UV-vis analysis (Beer-Lambert Law) as reported previously: ${ }^{40} \mathrm{FA}\left(n_{\text {mean }}=5.4,{ }^{1} \mathrm{H} \mathrm{NMR}\right)$; $\mathrm{TNB}$ (Dox) $\left(m_{\text {mean }}=5.1\right.$, UV-vis) (Table S1, Supporting Information).

Modular Integration of TNB(Dox) with UCN-PPIX. Among various light sources, long wavelength UVA is highly effective as a trigger for controlled release of photocaged compounds, though it faces certain limitations which are mostly related to its relatively poor tissue penetration. ${ }^{52}$ However, many of these issues are addressable by using photoluminescent UCNs as the nanoplatform. ${ }^{51}$ UCNs are excited by NIR $(980,800 \mathrm{~nm})$ light which displays deeper tissue penetration. ${ }^{52}$ Upon excitation by NIR, UCNs have an intrinsic mechanism by which they are able to upconvert this excitation energy to emission at shorter visible and UV bands. 
(A)
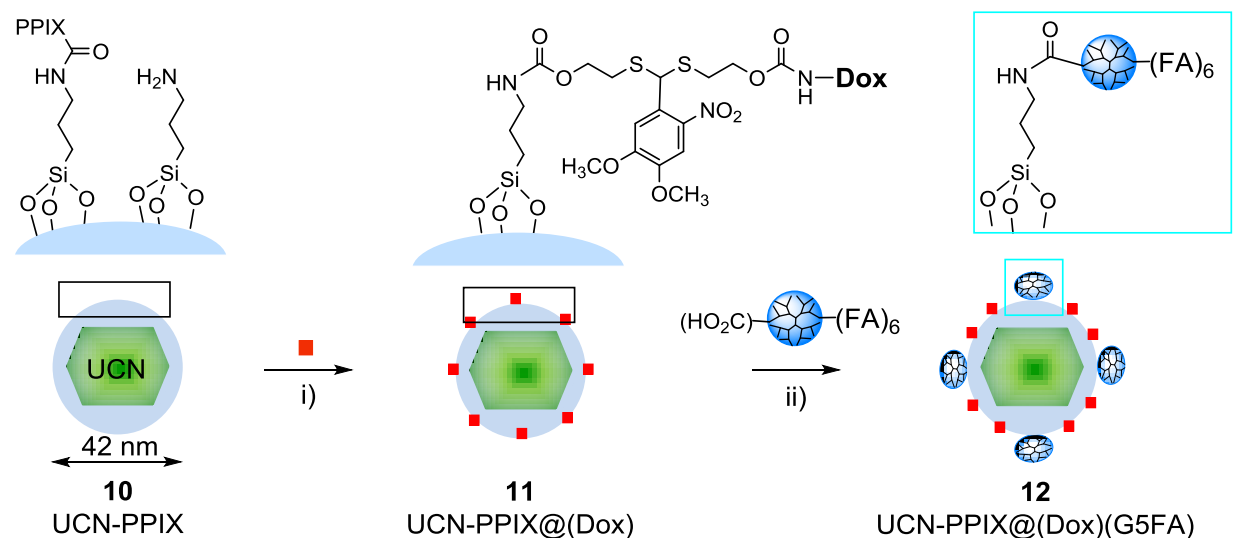

UCN-PPIX@(Dox)

UCN-PPIX@(Dox)(G5FA)

(B)

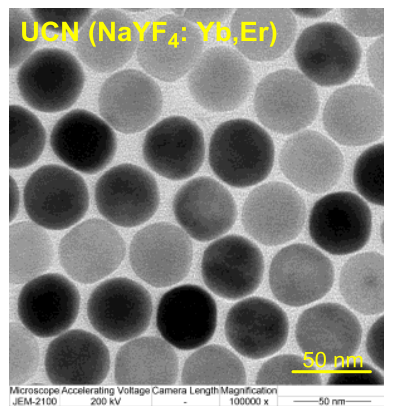

(E)

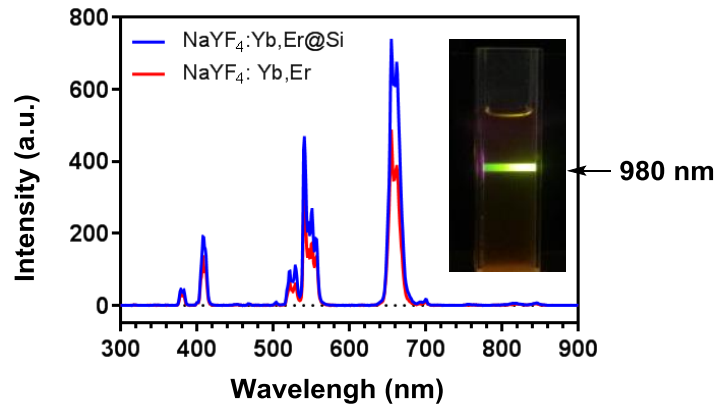

(C)

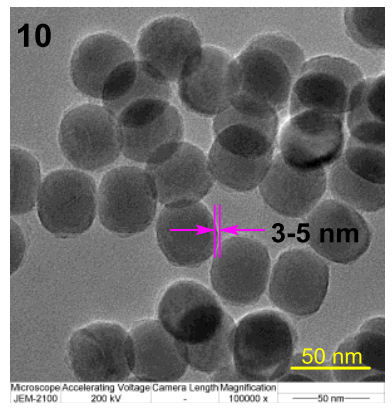

(D)

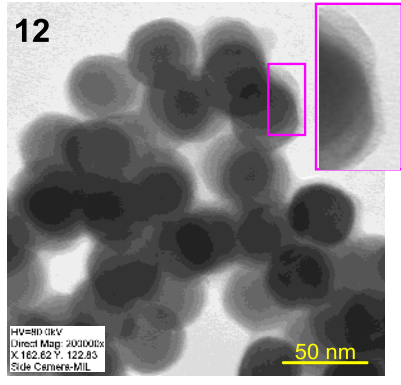

$(\mathrm{F})$

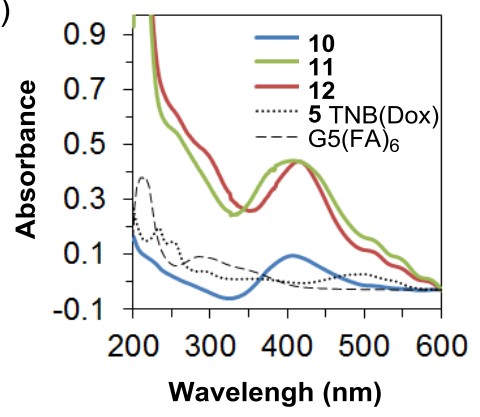

Figure 3. (A) Modular assembly and (B-F) physical and spectroscopic characterization of upconversion nanocrystal (UCN)s 10-12. Transmission electron microscopy (TEM) images of $\mathrm{UCN}\left(\beta-\mathrm{NaYF}_{4}: 20 \% \mathrm{Yb}, 2 \% \mathrm{Er}\right)(\mathrm{B}), \mathbf{1 0}$ (C), and 12 (D). (E) Upconversion luminescence spectra of UCNs acquired by excitation at $980 \mathrm{~nm}$. Inset: A photograph showing emitted light. (F) Overlaid UV-vis absorption spectra of UCNs 10-12 $(1.0 \mathrm{mg} / \mathrm{mL}$ in $\mathrm{MeOH})$. reagents and conditions: i) 4, MeOH, room temp; ii) G5(FA) $)_{6}, \mathrm{EDC}$, NHS, DMF, 36 h, room temp. UCN = $\mathrm{NaYF}_{4}: 20 \% \mathrm{Yb}, 2 \%$ Er. Abbreviations: UCN = upconversion nanocrystal; PPIX = protoporphyrin IX 
As described in our report ${ }^{36}, \mathbf{1 0}$ was prepared from $\mathrm{UCN}\left(\mathrm{NaYF}_{4}: 20 \% \mathrm{Yb}, 2 \% \mathrm{Er}\right)^{40}$ by surface coating with a thin siloxane polymer layer made of both protoporphyrin IX (PPIX)$\mathrm{Si}(\mathrm{OEt})_{3}$ and (3-aminopropyl)triethoxysilane (APTES) (Figure 3). The purpose of including this shell modification under a co-silanization condition was to incorporate PPIX as a photosensitizer to generate reactive oxygen species (ROS) as well to present an amine-coated surface for functionalization with $\mathrm{TNB}(\mathrm{Dox})$.

Surface amines in $\mathbf{1 0}$ were then used for conjugation with Dox through a TNB linker and with the G5(FA) 6 dendrimer which is introduced to serve as a FAR-targeting multivalent ligand $\left(K_{\mathrm{D}}=5.9 \times 10^{-9} \mathrm{M}\right.$ to folate binding protein $\left.{ }^{40}\right)$. This modular assembly was performed in a twostep reaction sequence, first by crosslinking with amine-reactive 4, which resulted in $\mathbf{1 1}$ through a chemically stable carbamate bond. Colorimetric analysis of the reaction mixture by UV-vis spectrometry $\left(\lambda_{\max }=400 \mathrm{~nm}\right)$ suggested $44.6 \%$ yield of $\mathrm{TNB}($ Dox $)$ conjugation which is equivalent to $4.3 \%(\mathrm{w} / \mathrm{w})$. In a second step, G5(FA) 6 was conjugated to 11 by an EDC-based amide coupling method, which resulted in $\mathbf{1 2}$. The efficiency of G5(FA) 6 conjugation was estimated as $12.3 \%$ by UV-vis analysis $\left(\lambda_{\max }=275 \mathrm{~nm}\right)$ of the reaction supernatant, which is equivalent to $3.1 \%(\mathrm{w} / \mathrm{w})$. These surface modifications of UCN-PPIX are evident in the overlaid UV-vis spectra of UCNs 10-12 in Figure 3F which show spectral features attributable to $\operatorname{TNB}($ Dox $)\left(\lambda_{\max }=445-512 \mathrm{~nm}\right)$ and G5(FA) $6\left(\lambda_{\max }=220,285 \mathrm{~nm}\right)$.

Physical properties of UCNs 10-12 were characterized by transmission electron microscopy (TEM) to determine their shape and size distributions (Figure 3B-3D). First, the core UCNs ( $\beta$ $\mathrm{NaYF}_{4}: 20 \% \mathrm{Yb}, 2 \% \mathrm{Er}$ ) were composed of hexagonal nanocrystals with an average diameter of $\sim 42 \mathrm{~nm}$ with a narrow distribution of size (range $=39-44)$. Their hexagonal lattice structure was 
previously confirmed by the analysis of selected area electron diffraction (SAED) patterns (inset). ${ }^{40}$ TEM images of core-shell nanostructured UCNs 11-12, each derived from 10, show similarities with $\mathbf{1 0}$ in their shape and size distributions. However, they show some minor, yet notable differences as compared to the parent $\mathrm{UCN}$ in their outer layers which appear to be less dense, but thicker than that of $\mathbf{1 0}$, which is supportive of surface modification with dendrimer and Dox molecules.

The photophysical properties displayed by the core $\mathrm{UCN}\left(\beta-\mathrm{NaYF}_{4}: 20 \% \mathrm{Yb}, 2 \% \mathrm{Er}\right)$ were investigated by NIR irradiation at $980 \mathrm{~nm}$ in a continuous wave $(\mathrm{CW})$ mode $(1 \mathrm{~W}$; output $=\sim 5 \times$ $10^{18}$ photons s${ }^{-1}$ ). This UCN shows a luminescent property composed of three UV-vis emission peaks (Figure 3E), each assigned to $\mathrm{Er}^{3+}$ upconversion transition including a weak UV band $\left(\lambda_{\max }\right.$ $\left.=380,410 \mathrm{~nm} ;{ }^{4} \mathrm{G}_{11 / 2} /{ }^{2} \mathrm{H}_{9 / 2} \rightarrow{ }^{4} \mathrm{I}_{15 / 2}\right)$, and two strong bands at green $\left(\lambda_{\max }=550 \mathrm{~nm} ;{ }^{4} \mathrm{~S}_{3 / 2} \rightarrow\right.$ $\left.{ }^{4} \mathrm{I}_{15 / 2}\right)$ and red $\left(\lambda_{\max }=651 \mathrm{~nm} ;{ }^{4} \mathrm{~F}_{9 / 2} \rightarrow{ }^{4} \mathrm{I}_{15 / 2}\right)$ wavelengths. ${ }^{53}$

Photolysis of TNB(Dox). We next investigated the efficiency of the photolytic cleavage of 5 $\left(20 \% \mathrm{MeOH} / \mathrm{H}_{2} \mathrm{O}\right.$ ) by long wavelength UVA (Figure 4). Like the photolinker 1 itself, which showed a rapid decrease in absorbance at its $\lambda_{\max }$ at $346 \mathrm{~nm}\left(\varepsilon=4,292 \mathrm{M}^{-1} \mathrm{~cm}^{-1}\right),{ }^{48}$ the UV-vis spectral traces of this TNB-caged Dox showed a similar decrease in absorbance at $\lambda_{\max } 355 \mathrm{~nm}$ with no apparent change in the Dox absorbance $\left(\lambda_{\max } 497 \mathrm{~nm}\right)$. Kinetic analysis of TNB absorption traces suggests that its photolysis occurs rapidly with a first order rate constant $\left(k_{\text {obsd }}\right.$ $=0.181 \mathrm{~min}^{-1}$, Figure 4B). 

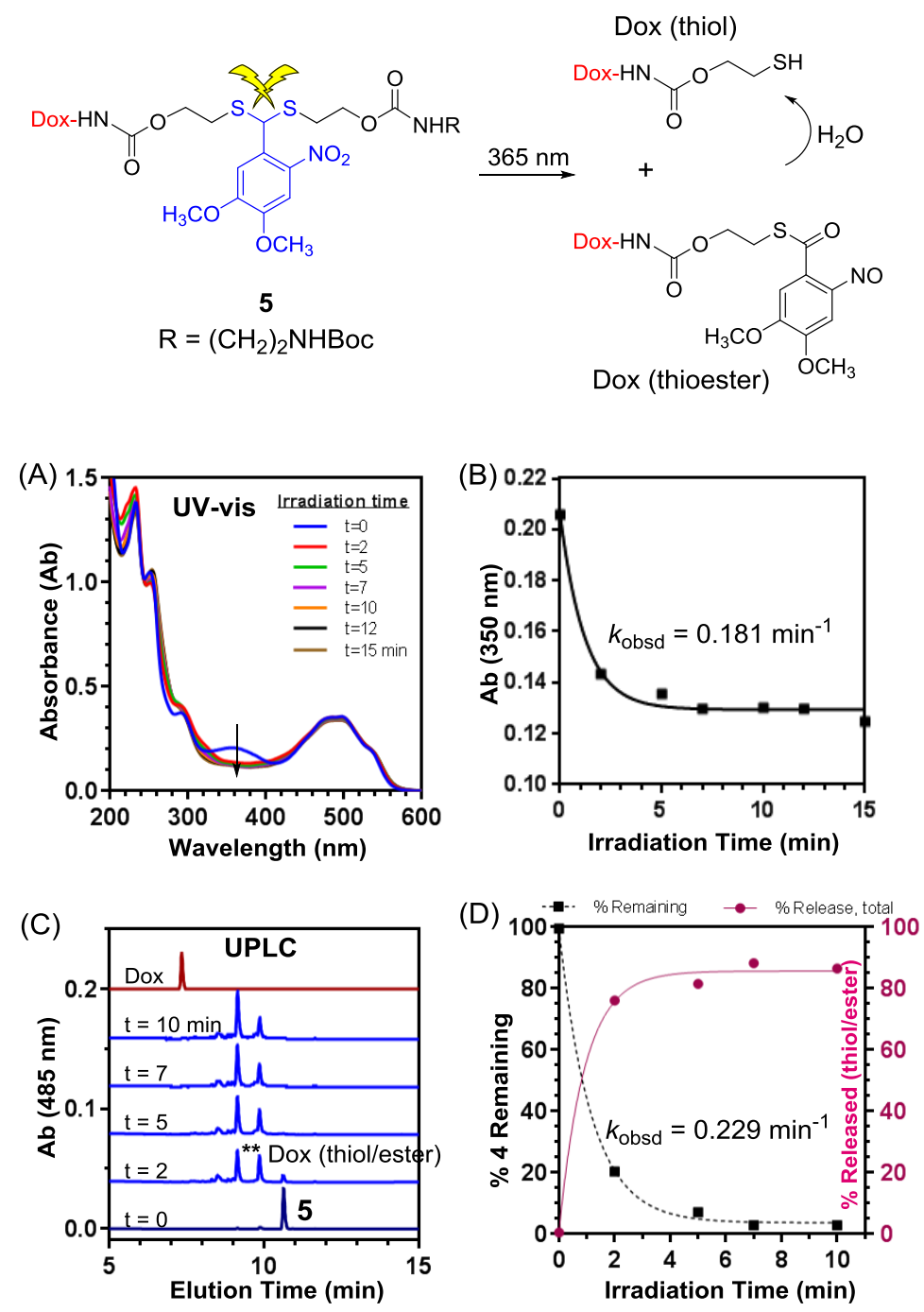

Figure 4. Photolysis of TNB-caged doxorubicin (Dox) in $\mathbf{5}$ in aqueous methanol by UVA (365 $\mathrm{nm})$. (A, B) Overlaid UV-vis spectral traces and changes in absorbance $\left(A b_{350}\right)$ as a function of light exposure time: $[5]_{\mathrm{t}=0}=4.53 \times 10^{-5} \mathrm{M}$. $(\mathrm{C}, \mathrm{D})$ UPLC traces and the kinetic analysis of Dox release: $[5]_{\mathrm{t}=0}=9.05 \times 10^{-5} \mathrm{M}$.

UPLC analysis was performed to identify the photolytic products of 5 (Figure 4C). Its traces showed the appearance of two major peaks, each appearing at a shorter retention time than its parent 5. This result is consistent with the anticipated mechanism of concomitant release of two Dox-terminated species, proposed to be Dox(thiol) and Dox(thioester). An LC-MS analysis performed after $5 \mathrm{~min}$ of irradiation showed a peak at $\mathrm{m} / \mathrm{z} 686.2486$ which points to the release 
of Dox(thiol) (calcd for $\mathrm{C}_{30} \mathrm{H}_{33} \mathrm{KNO}_{13} \mathrm{~S}[\mathrm{Dox}(\text { thiol })+\mathrm{K}]^{+}$, found 686.1310). The decay of $\mathbf{5}$ occurred following an exponential curve, and its area under curve (AUC) analysis led to an observed rate constant $k_{\text {obsd }}$ of $0.221 \mathrm{~min}^{-1}$ which is close to the value $\left(0.118 \mathrm{~min}^{-1}\right)$ calculated from its UV-vis analysis above. The quantum yield of $\mathbf{5}$ in TNB cleavage $\left(\Phi_{\text {cleavage }}=0.22\right)$ which was determined relative to ferrioxalate actinometry $(\Phi=1.26)$, indicates that its cleavage occurs as efficiently as its parent linker $\mathbf{1}\left(\Phi_{\text {cleavage }}=0.19\right)^{48}$ apparently without any effect from Dox conjugation.
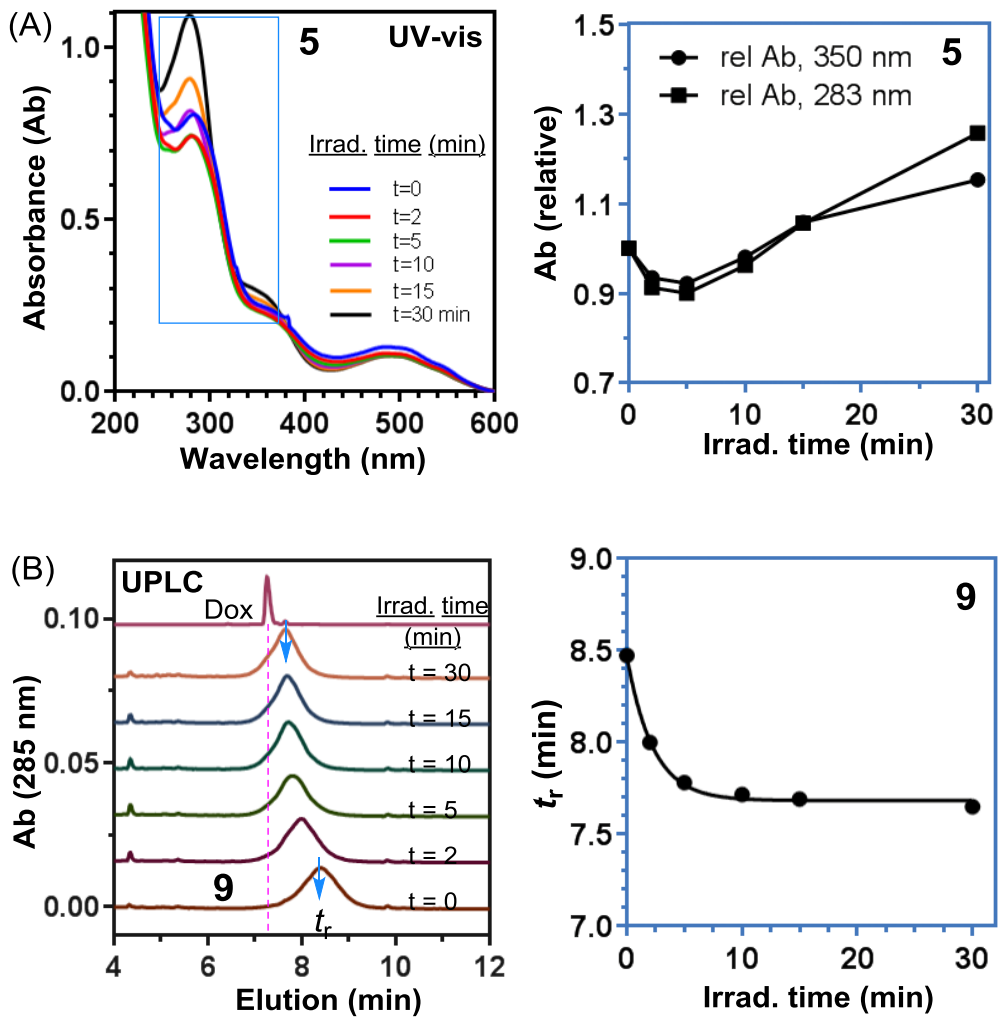

Figure 5. Photolysis of 9 G5(FA) $)_{5.4}(\text { Dox })_{5.1}$ conjugate. (A) Overlaid UV-vis spectra and (B) UPLC traces of $9\left(3.52 \times 10^{-6} \mathrm{M}\right.$ in PBS, pH 7.4) after exposure to UVA (365 nm). Relative absorbance $(\mathrm{Ab})$ values at each detection wavelength (A, right) are calculated by normalization to an initial value $\left(\mathrm{Ab}_{\mathrm{t}=0}\right)$ measured prior to irradiation. Abbreviation: $t_{\mathrm{r}}=$ retention time 
Photolysis of TNB(Dox)-caged Dendrimer. Kinetic studies of Dox release by UVA light were continued with the dendrimer conjugate 9 by monitoring its progress with UV-vis spectrometry and UPLC (Figure 5). Changes in the absorbance corresponding to Dox at $490 \mathrm{~nm}$ appeared to be insignificant in the spectral traces, however, significant changes in absorbance were observed at shorter wavelengths of $283 \mathrm{~nm}$ and $350 \mathrm{~nm}$, which are associated with the absorbance of FA and TNB, respectively. The absorbance at $350 \mathrm{~nm}$ decreased rapidly, reaching a minimum around 5 min as seen with 5 (Figure 4A), however it gradually increased (Figure 5A, right). Such absorption features are partly consistent with those observed in the photolysis of a comparable ONB(Dox)-conjugated dendrimer under a similar condition. ${ }^{5}$ These might be attributable to the subsequent oxidation of a nitrosobenzoyl group tethered at the dendrimer to its corresponding nitrobenzoyl group which could restore a higher molar absorptivity. In addition, complexation of released Dox species in the hydrophobic environment surrounded with dendritic branches may also contribute to this growth.

UPLC analysis of the photolysed solutions of $\mathbf{9}$ showed an irradiation time-dependent course of peak shifts as shown by overlaid UPLC traces (Figure 5B). Prior to irradiation, 9 appears as a broad peak (retention time $t_{\mathrm{r}}=8.4 \mathrm{~min}$ ), which could be attributable to the broad distributions in valencies of FA $(\mathrm{n}=1-11$; mean $=5.4$; median $=6)$ and Dox $(\mathrm{m}=1-10$; mean $=5.1$; median $=$ 5) as predicted by a Poisson simulation ${ }^{54}$ (Figure S2, Supporting Information). In response to increased exposure times, this broad peak shifted towards a shorter $t_{\mathrm{r}}$, rapidly reaching a plateau (Figure 5B, right). However, peaks for released Dox species were not resolvable from the broader dendrimer peaks, and they might be entirely buried within the dendrimer peaks. The elution profiles of 9 were observed similarly with the UPLC analysis of the ONB(Dox)- 
conjugated dendrimer G5(FA) 6 (Dox $)_{6.9}$, in which the shorter $t_{\mathrm{r}}$ values were attributable to smaller NP sizes obtained as a result of Dox release. ${ }^{40}$

In summary, the photolysis results of $\mathbf{5}$ and its dendrimer conjugate $\mathbf{9}$ suggest certain similarities in the photochemical properties between the TNB and ONB linker. First, Dox release occurs rapidly in both $\mathrm{TNB}$ (Dox) and $\mathrm{ONB}($ Dox $),{ }^{40}$ each achieving $\geq 80 \%$ linker cleavage after only 4 min of UVA exposure. Second, TNB cleavage occurs more slowly in its dendrimer conjugate 9 than its unconjugated form $\mathbf{5}$, as was the case for ONB(Dox) and its dendrimer conjugate in a corresponding study. ${ }^{40}$ This lowered efficiency is proposed to be caused by the FA co-attached to the dendrimer as its pteridine chromophore has a strong molar absorptivity in the UV region $\left(\lambda_{\max }=354 \mathrm{~nm} ; \varepsilon=62,800 \mathrm{M}^{-1} \mathrm{~cm}^{-1}\right)$ and can competitively absorb a fraction of the UV excitation.
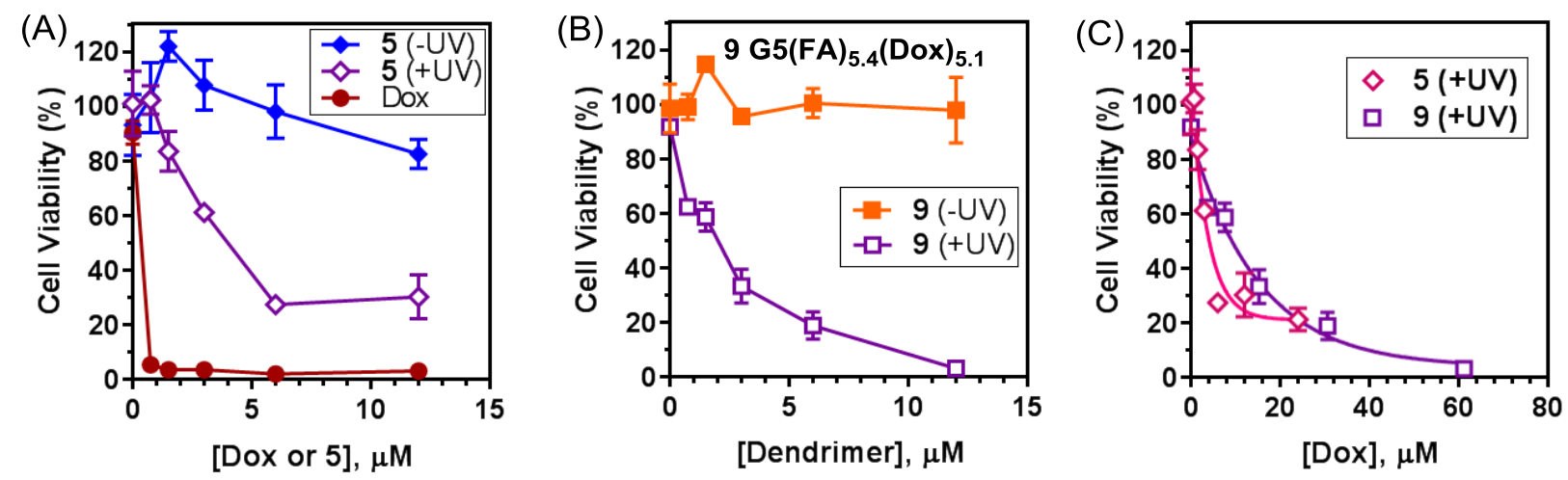

Figure 6. Light control of the cytotoxicity of 5 TNB(Dox)(NHBoc) (A), 9 G5(FA) 5.4(Dox) $_{5.1}$ (B) and comparison of their toxicities on a Dox basis (C). Cellular viability was measured in FAR(+) KB tumor cells in vitro with or without exposure to UVA (365 nm). Error bars invisible in Dox and $+\mathrm{UV}$ data points are buried within the symbols. Mean $\pm \mathrm{SD}(\mathrm{N}=2)$.

Light-controlled Cytotoxicity of TNB(Dox) and its Dendrimer Conjugate. We next investigated the ability of light to modulate the cytotoxicity of $\mathbf{5}$ in FAR overexpressing KB 
cells, an epithelial carcinoma cell line. Cells were initially incubated with the test compounds for a total of 30 min for both +UVA and -UVA samples. The -UVA cells were then incubated at 37 ${ }^{\circ} \mathrm{C}$ for an additional $24 \mathrm{~h}$. For +UVA cells, treated cells were exposed to UVA for 10 min prior to the same incubation at $37{ }^{\circ} \mathrm{C}$ for $24 \mathrm{~h}$. The media was then replaced with fresh media after the incubation, and the cells were grown for 4 more days prior to measuring the cellular viability by an XTT assay. As summarized in Figure 6A, 5 displayed minimal cytotoxicity without light exposure, even at high concentrations ( $\geq 80 \%$ viability at up to $25 \mu \mathrm{M}$ ), as anticipated for the caged drug molecule. In contrast, unmodified Dox displayed potent cytotoxicity at low concentrations $(\leq 10 \%$ viability at $1 \mu \mathrm{M})$. After $10 \mathrm{~min}$ of exposure to UVA, the viability of cells treated with 5 reduced in a dose-dependent manner to $\leq 30 \%$ at concentrations $\geq 6 \mu \mathrm{M}$ (Figure 6B), indicative of light-induced cytotoxicity. As a control, untreated KB cells were exposed to UVA light for the same period, and no effect on cell viability was observed, which is consistent with earlier results. ${ }^{40,48}$ The maximal level of cytotoxicity by $\mathbf{5}$ is, however, lower than that of free Dox. It might be associated with the release of Dox(thiol) and Dox(thioester) (Figure 2), and their relatively slow conversion to free Dox in the cells. ${ }^{48}$

Conjugate 9 was similarly investigated for its cytotoxicity in FAR(+) KB cells. As seen with 5, it lacked intrinsic cytotoxicity but became cytotoxic in a dose-dependent manner to the tumor cells when triggered by UVA exposure (Figure 6B). The FAR-targeted dendrimer conjugate showed a greater extent of cytotoxicity $(<10 \%$ in viability) at the highest dose compared to the untargeted conjugate $\mathbf{5}$. We attribute this greater extent of cytotoxicity by $\mathbf{9}$, in part, to its multivalent ligand design that confers tight, FAR-specific binding to cellular surface receptors $\left(K_{\mathrm{D}}=1.7 \times 10^{-8} \mathrm{M}\right.$; multivalent FA 9 to folate binding protein $) .{ }^{5,40}$ Furthermore, FAR-mediated endocytosis $^{55}$ of the surface receptor bound dendrimer may lead to more efficient intracellular 
uptake, further enhancing Dox delivery. ${ }^{5,40}$ Dendrimer facilitated uptake of Dox, was supported by wash-out experiments, in which KB cells were treated with $\mathbf{5}$ or $\mathbf{9}$ for 30 min followed by extensive washing of the cells prior to UVA exposure. While $\mathbf{5}$ showed minimal toxicity after washing, 9 still showed significant light-triggered cytotoxicity, supporting the intracellular uptake of the dendrimer prior to the wash step (data not shown). When compared on a per Doxbasis, however, the light-induced cytotoxicity of dendrimer conjugate 9 appeared slightly reduced compared to $\mathbf{5}$ (Figure 6C), which is likely attributable to the slower rate of TNB cleavage in 9 (Figure 5) and the slow kinetics of Dox(thiol) and Dox(thioester) conversion to Dox (Figure 2).

Cellular FAR Targeting and Binding of UCN Conjugates In Vitro. In our previous report, ${ }^{40}$ we were able to detect the UCN conjugate bound and internalized in KB cells by confocal microscopy using the NIR luminescence $\left(\lambda_{\text {ex }}=980 \mathrm{~nm} ; \lambda_{\text {ex }}=550,650 \mathrm{~nm}\right)$ of the nanoparticle. The NIR luminescent properties of the UCN core allow for imaging without the need for labelling with an exogenous fluorophore. We applied the same technique to evaluate the tumor targeting capability of current UCN conjugates in FAR $(+)$ KB cells. Figure 7 (A, B) shows images of $\mathrm{KB}$ cells treated with $\mathbf{1 1}$ or $\mathbf{1 2}$, each at $500 \mu \mathrm{g} / \mathrm{mL}$ for $2 \mathrm{~h}$ at $37^{\circ} \mathrm{C}$. Cellular binding and uptake were dramatically increased for 12, the FAR-targeted UCN coated with G5(FA)6, compared to 11, which lacks the targeting dendrimer. A similar set of imaging experiments were performed in FAR(-) B16 cells in vitro (Figure 7C, 7D), which did not show as much binding for either $\mathbf{1 1}$ or $\mathbf{1 2}$ as for the $\mathrm{KB}$ cells, however there was no significant difference found between the cells treated with $\mathbf{1 1}$ or 12. In fact, $\mathbf{1 2}$ appeared to bind slightly less to the FAR(-) cells than $\mathbf{1 1}$. These results are supportive of the FAR specificity of $\mathbf{1 2}$ in $\mathrm{KB}$ cells. 
(A)

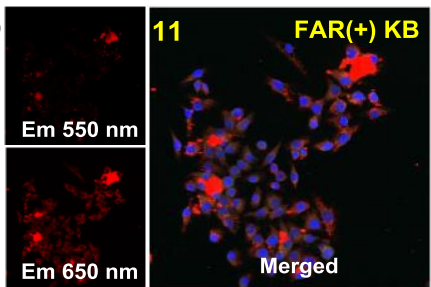

(C)
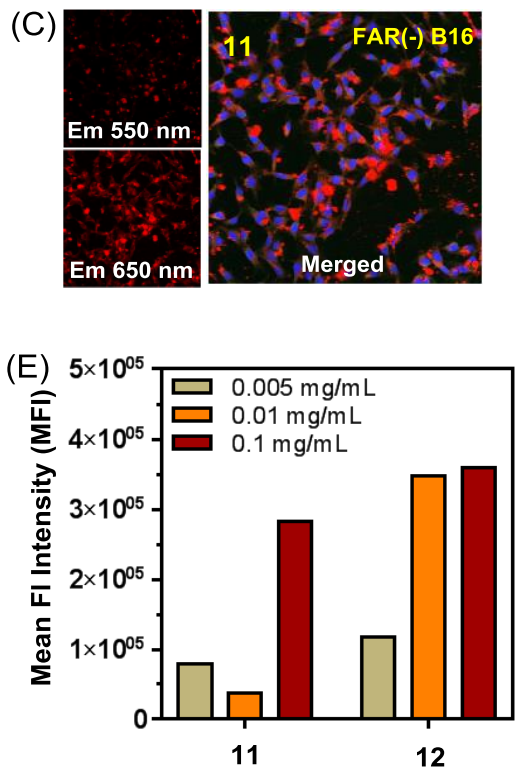

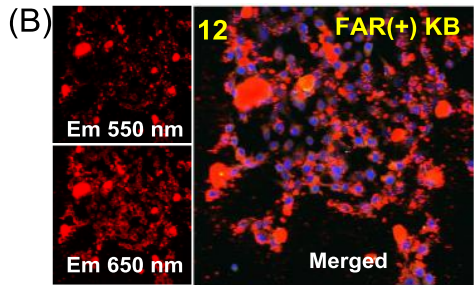

(D)

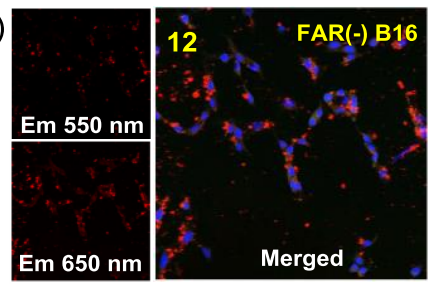

$(\mathrm{F})$

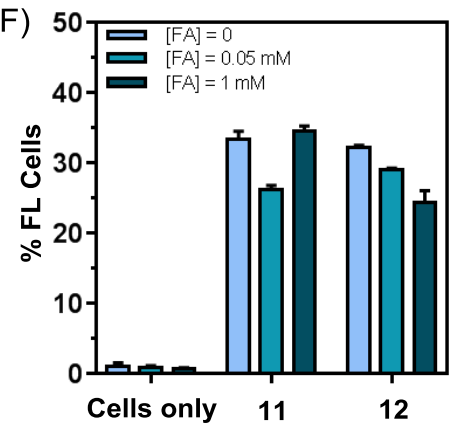

Figure 7. Cellular binding and flow cytometric analysis of UCN conjugates in vitro. Fluorescence confocal microscopy images of FAR $(+)$ KB cells $(\mathrm{A}, \mathrm{B})$ or FAR $(-)$ B16 cells $(\mathrm{C}$, D) treated with 11 UCN-PPIX@(Dox) or 12 UCN-PPIX@(Dox)(G5FA), each at $500 \mu \mathrm{g} / \mathrm{mL}$, imaged by NIR luminescence $\left(\lambda_{\mathrm{ex}}=980 \mathrm{~nm} ; \lambda_{\mathrm{em}}=550 \mathrm{~nm}, 650 \mathrm{~nm}\right)$. Color codes: DAPI (blue: nuclei), UCN (red). (E, F) Flow cytometry analysis of FAR(+) KB cells incubated with Cy5labeled 11 and 12 for $1 \mathrm{~h}$ at $37{ }^{\circ} \mathrm{C}$. Cellular binding and/or uptake of the conjugates was determined by the cell associated mean fluorescence intensity (MFI) in the Cy5 channel and expressed as a function of the UCN dose (E). Competitive ligand displacement of KB cells by co-incubation of Cy5-labeled 11 or 12 (each at $0.1 \mathrm{mg} / \mathrm{mL}$ ) with increasing concentrations of free folate (F). Cell-associated fluorescence was measured in a Cy5 channel. Mean $( \pm \mathrm{SD})$.

This difference observed by confocal microscopy was further evaluated by flow cytometric analysis performed using Cy5-labeled 11 or 12 in $\mathrm{KB}$ cells $([\mathbf{1 1}$ or 12] $=5,10,100 \mu \mathrm{g} / \mathrm{mL}$; 
Figure 7E). Comparison of the mean fluorescence intensity (MFI) of the population of bound cells demonstrates that $\mathbf{1 2}$ exhibits dose-dependent binding, yielding higher MFIs than the nontargeted UCN 11 at the lower concentrations. For example, at the $10 \mu \mathrm{g} / \mathrm{mL}$ concentration, UCN $\mathbf{1 2}$ had a nearly 7-fold higher MFI than $\mathbf{1 1}$. While $\mathbf{1 1}$ showed minimal or no binding at the lower concentrations, at the highest dose $(100 \mu \mathrm{g} / \mathrm{mL})$ a significant amount of binding was observed. This is likely due to nonspecific binding attributable to electrostatic interactions between the positively charged $\mathbf{1 1}$ and the cell membrane surface ${ }^{56}$ However, the amount of binding of $\mathbf{1 1}$ even at this highest dose was still lower than that of the targeted UCN 12. Furthermore, the slightly greater nonspecific binding observed by flow for $\mathbf{1 1}$ compared to the confocal analysis may also be due to the presence of the Cy5 fluorophore on the UCNs used for flow analysis which was not present on the UCNs in the confocal studies. Binding of $\mathbf{1 2}$ however, shows FAR specificity as evidenced by the ability of free FA to compete for its binding to FAR $(+) \mathrm{KB}$ cells (Figure 7F). In the ligand displacement assay, the KB cells were co-incubated with excess FA $\left(K_{\mathrm{D}}=5.9 \times 10^{-6} \mathrm{M}\right){ }^{40}$ added at increasing concentrations prior to addition of the UCNs. The percentage of cells containing bound UCN decreased for UCN 12 by $10 \%$ at $1 \mathrm{mM}$ FA, but did not change for UCN 11 even at the high FA concentration. However, the lack of complete displacement by FA is indicative of the tight adsorption of multivalent G5(FA) 6 to the cell surface receptors which displays high binding avidity $\left(K_{\mathrm{D}}=5.9 \times 10^{-9} \mathrm{M}\right){ }^{40}$ These results demonstrate the ability of the G5(FA) $)_{6}$ dendrimer to impart FAR targeting to the UCN complex, and show that attachment to the UCN did not interfere with the binding of G5(FA) 6 to surface FAR. 

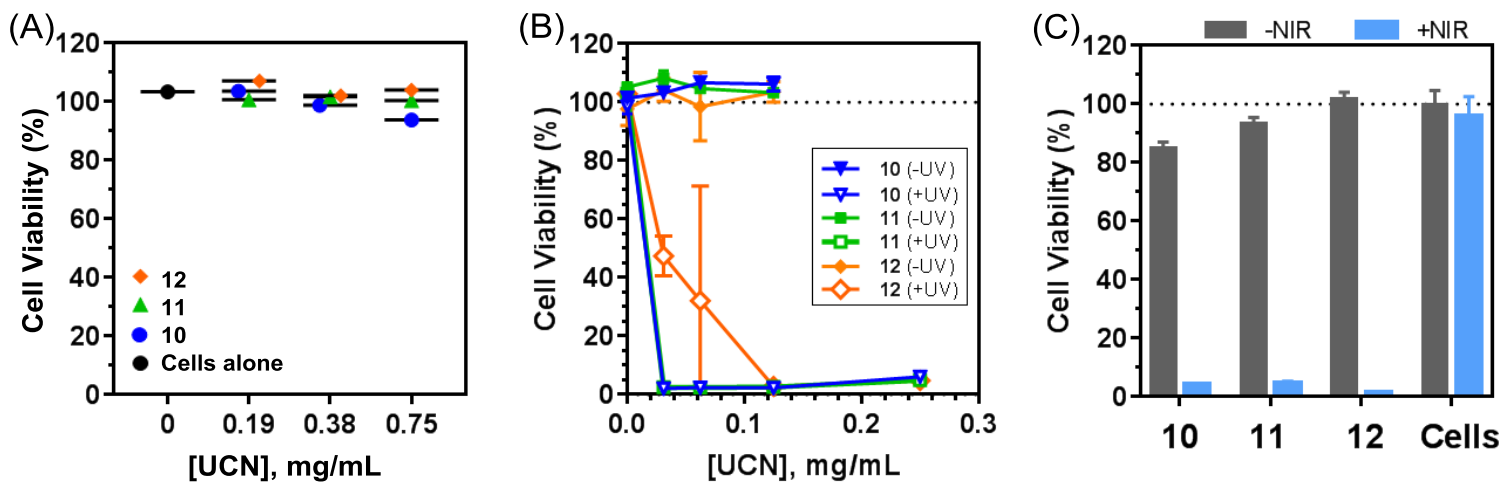

Figure 8. Controlled cytotoxicity of 10 UCN-PPIX, 11 UCN-PPIX@(Dox), and 12 UCNPPIX@(Dox)(G5FA) in FAR(+) KB cells in vitro. Cell viability of UCN treated cells was measured without light exposure (A), or after exposure to UVA (365 nm, $10 \mathrm{~min}$ ) (B) or NIR $(980 \mathrm{~nm}, 1 \mathrm{~h})[\mathrm{UCN}]=0.75 \mathrm{mg} / \mathrm{mL})(\mathrm{C})$. Mean $\pm \mathrm{SD}(\mathrm{N}=2-4)$.

Light-controlled Cytotoxicity of UCN Conjugates. To characterize the efficiency of UCN conjugates 10-12 in inducing cytotoxicity in a light-modulated manner, cytotoxicity assays were performed in KB cells (Figure 8). This cytotoxicity assay was performed similarly to our prior study, ${ }^{40}$ in which the cells were incubated at $37{ }^{\circ} \mathrm{C}$ for $30 \mathrm{~min}$ with each UCN conjugate at variable concentrations $([\mathrm{UCN}]=0.03-0.75 \mathrm{mg} / \mathrm{mL})$ to allow cellular binding and uptake, and exposed to either UVA $(365 \mathrm{~nm})$ for $10 \mathrm{~min}$ or NIR $(980 \mathrm{~nm})$ for $1 \mathrm{~h}$. After light exposure, the cells were treated as described for Figure 6 prior to performing an XTT assay for measurement of cell viability.

As shown in Figure 8A, incubation with 10-12 without light exposure led to normal growth and viability, indicating a lack of intrinsic cytotoxicity by each UCN conjugate except 10 which showed a low level of cytotoxicity at its highest dose $(0.75 \mathrm{mg} / \mathrm{mL})$. However, subsequent UVA exposure led to a large decrease $(\mathbf{1 0}, \mathbf{1 1})$ or dose-dependent decrease $(\mathbf{1 2})$ in cell viability. First, 10 which lacks Dox displays very potent cytotoxicity upon UVA exposure. This potent 
cytotoxicity is consistent with our previous results, ${ }^{36}$ and is attributable to the mechanism of the photodynamic activation of PPIX molecules in the shell layer $\left(\lambda_{\max }=408 \mathrm{~nm}\right.$, Figure $\left.3 \mathrm{G}\right)$, by which cytotoxic ROS could be generated. Second, 12, the FAR-targeted conjugate which is more effective in cellular binding than 11 in FAR(+) KB cells (Figure 7), showed otherwise a slightly reduced cytotoxicity. We believe this lower activity might be attributable partly to slower drug release due to the absorbance of UVA radiation by the G5(FA) 6 on the surface and/or the delayed metabolic conversion of released Dox species as suggested for 9 (Figure 6). In summary, each UCN conjugate which carries the PPIX photosensitizer alone or in combination with TNB-caged Dox showed highly effective UV light-dependent cytotoxicity in tumor cells.

Use of NIR (980 nm) was then studied to control the cytotoxicity of UCN conjugates $\mathbf{1 0}-\mathbf{1 2}$. $\mathrm{FAR}(+) \mathrm{KB}$ cells were incubated with each conjugate at $750 \mu \mathrm{g} / \mathrm{mL}$, a high dose selected to achieve a sufficient level of cell binding for comparison (Figure 7E), and the treated cells were exposed to NIR radiation $(980 \mathrm{~nm})$ for $1 \mathrm{~h}$. Figure $8 \mathrm{C}$ compares the cell viability in the presence of the three conjugates measured with/without NIR exposure. Under the no NIR condition, the two non-targeted conjugates $\mathbf{1 0}$ and 11, showed some cytotoxicity, each causing $\sim 15 \%$ and $\sim 10 \%$ reduction in cellular viability, respectively, compared to 12 which lacked such intrinsic toxicity. Exposure of the UCN treated cells to NIR had a significant impact on the cell viability, but NIR exposure alone had no impact on cells in the absence of UCN (Figure 8C). Each of the UCN conjugates was equally effective and almost indistinguishable in inducing potent cytotoxicity, resulting in less than $5 \%$ cell survival. This result might be attributable to the additivity of at least three effects, each contributed by the intrinsic toxicity of UCN-PPIX, the potent ROS mechanism of PDT, ${ }^{36}$ and the release of Dox species. However, it is notable that 12 appears to be the most desirable delivery system due to its lack of intrinsic toxicity, FAR-specific 
cell binding, and NIR-inducible cytotoxicity. While not as critical in a closed in vitro system, where free drug is maintained in the media upon release, the large enhancement in UCN binding and targeting specificity facilitated by the attached G5(FA) ${ }_{6}$ dendrimer may be more important in vivo where circulation of interstitial fluid makes concentrated and localized delivery critical for maximal impact and minimal systemic toxicity.

In summary, this study describes the kinetics and effects of Dox release from these TNBcaged Dox conjugates with the light trigger in solution and FAR-overexpressing (+) KB tumor cells in vitro. The rapid release kinetics was observed upon UVA light stimulation in solution, and it was consistent with their observed ability to potently induce cytotoxicity in the tumor cells as modulated by exogenous light triggers. Furthermore, the UCN core/shell nanoconjugates were investigated for FAR-specific cellular uptake and NIR imaging by confocal microscopy without the need for an added fluorophore due to the intrinsic luminescence properties of the UCN core. The findings of this current study present significant insights on the new TNB-based conjugate system by presenting several sets of data supportive of its synthetic practicality, conjugation modularity demonstrated with two representative NPs, and its applicability for light-controlled drug cytotoxicity.

\section{Conclusion}

First, we have demonstrated the design of a dual-arm TNB linker and its utility for lightcontrolled Dox delivery in two representative nanoscale platforms. This TNB strategy has significant potential for enhancing our capability to advance the field of controlled delivery technologies by addressing the synthetic challenges and lengthy procedures often associated with

drug-NP conjugation. ${ }^{5,6}{ }^{47}$ Currently, several classes of photolinkers ${ }^{26,44}$ have been developed 
for light-controlled delivery, each based on the scaffold of ONB, ${ }^{4-6,27}$ coumarin, ${ }^{43}$ carbazole ${ }^{57}$ and cyanine. ${ }^{58}$ Compared to these photoactive linkers, $\mathrm{TNB}^{48}$ is validated as an important tool in this study due to its unique benefits such as its symmetric structure, synthetic convenience, and large scale accessibility.

Second, this study investigated the specific capability and efficiency of the TNB-Dox conjugation method by its application to known drug delivery systems including dendrimer conjugates $^{2,5,17}$ and modularly integrated UCNs. ${ }^{36,40}$ Integration of multiple functionally distinct components into a single nanostructure could be challenging in this field, but this study illustrates an improved process for NP-drug conjugation using a TNB-caged Dox payload in two distinct nanostructures represented by dendrimer polymers or photonic UCNs.

Third, each of the two FAR-targeted NPs reported here offers the ability to actively control drug delivery using either UVA or NIR which triggers drug release indirectly by UVA emitted from the UCN core. Given the recent advances in optical fiber technologies, each delivery system suggests potential for enabling spatially and temporally restricted drug release to various FAR $(+)$ tumor cells localized in the epidermis or vascular endothelia using a UVA or NIR laser which allow for much deeper tissue penetration beyond the epidermal layers. ${ }^{52}$ Future efforts will be directed towards advancing the scope of the thioacetal strategy by expanding its use to other classes of photocages such as coumarin for wavelength-selective release.

\section{Experimental Section}

Materials, general synthetic methods and analytical methods $\left({ }^{1} \mathrm{H}\right.$ NMR, UV-vis spectrometry, mass spectrometry, UPLC, TEM) are detailed in Supporting Information. 
$1 \mathbf{T N B}(\mathbf{O H})$. The detailed synthesis of 1 was reported in our earlier publication. ${ }^{48}$ In short, this thioacetal was prepared in one step from 4,5-dimethoxy-6-nitrobenzaldehyde (6nitroveratraldehyde) by reacting with 2 -mercaptoethanol $(2 \times 2.5$ mol equiv $)$ in dichloromethane containing a mixture of acetic acid and $\mathrm{BF}_{3} \cdot \mathrm{Et}_{2} \mathrm{O}$ as a catalyst. MS (ESI) $\mathrm{m} / z$ (relative intensity, \%): calcd 372.06 for $\mathrm{C}_{13} \mathrm{H}_{19} \mathrm{NNaO}_{6} \mathrm{~S}_{2}[\mathrm{M}+\mathrm{Na}]^{+}$; found 372.0 (10), 212.0 (100). ${ }^{1} \mathrm{H}$ NMR (500 $\left.\mathrm{MHz}, \mathrm{CD}_{3} \mathrm{OD}\right): \delta 7.55\left(\mathrm{~s}, 1 \mathrm{H}, \mathrm{H}_{\mathrm{a}}\right), 7.50\left(\mathrm{~s}, 1 \mathrm{H}, \mathrm{H}_{\mathrm{b}}\right), 6.09\left(\mathrm{~s}, 1 \mathrm{H}, \mathrm{H}_{\mathrm{c}}\right), 3.95\left(\mathrm{~s}, 3 \mathrm{H}, \mathrm{H}_{\mathrm{d}}\right), 3.90(\mathrm{~s}$, $\left.3 \mathrm{H}, \mathrm{H}_{\mathrm{d}^{\prime}}\right), 3.68-3.66\left(\mathrm{t}, J=7 \mathrm{~Hz}, 4 \mathrm{H}, \mathrm{H}_{\mathrm{e}}\right), 2.83-2.78\left(\mathrm{~m}, 2 \mathrm{H}, \mathrm{H}_{\mathrm{f}}\right), 2.70-2.65\left(\mathrm{~m}, 2 \mathrm{H}, \mathrm{H}_{\mathrm{f}}\right) \mathrm{ppm}$. UV-vis $\left(10 \%\right.$ aqueous methanol): $\lambda_{\max }=346\left(\varepsilon=4,292 \mathrm{M}^{-1} \mathrm{~cm}^{-1}\right), 248\left(\varepsilon=11,560 \mathrm{M}^{-1} \mathrm{~cm}^{-1}\right) \mathrm{nm}$.

3 TNB(4-NP) (Scheme 1). To a stirred solution of 1 (200 mg, $0.573 \mathrm{mmol})$ and $N, N$ diisopropylethylamine $(0.43 \mathrm{~mL}, 2.40 \mathrm{mmol})$ in chloroform $(4 \mathrm{~mL})$ was added a solution of 4 nitrophenyl chloroformate $(242 \mathrm{mg}, 1.20 \mathrm{mmol})$ in anhydrous tetrahydrofuran $(2 \mathrm{~mL})$. The mixture was stirred at room temp overnight, and followed by the addition of a second portion of 4-nitrophenyl chloroformate (242 mg, $1.20 \mathrm{mmol}$ ) and 4-dimethylaminopyridine (147 mg, 1.20 mmol). After stirred for an additional period of $3 \mathrm{~h}$, the mixture was concentrated in vacuo, and the residue was dissolved in $10 \mathrm{~mL}$ of ethyl acetate. The organic solution was washed with a cold saturated sodium bicarbonate solution $(5 \mathrm{~mL})$ and water $(5 \mathrm{~mL})$, and then dried over anhydrous sodium sulfate. After concentration in vacuo, the crude product was purified by flash column chromatography (silica gel) by eluting with ethyl acetate/hexane (1:5 to $1: 2$ ). The desired product was obtained as a pale yellow syrup ( $232 \mathrm{mg}, 60 \%)$. TLC (1:1 ethyl acetate/hexane): $R_{f}=0.63$. MS (ESI) $m / z$ (relative intensity, \%): calcd 702.07 for $\mathrm{C}_{27} \mathrm{H}_{25} \mathrm{~N}_{3} \mathrm{NaO}_{14} \mathrm{~S}_{2}[\mathrm{M}+\mathrm{Na}]^{+}$; found 702.0 (6.9), 437 (100). ${ }^{1} \mathrm{H}$ NMR (500 MHz, $\left.\mathrm{CDCl}_{3}\right): 8.28-8.26$ (d, $\left.J=10 \mathrm{~Hz}, 4 \mathrm{H}, 4-\mathrm{NP}\right), 7.53$ (s, $1 \mathrm{H}$, $\left.\mathrm{H}_{\mathrm{a}}\right), 7.45\left(\mathrm{~s}, 1 \mathrm{H}, \mathrm{H}_{\mathrm{b}}\right), 7.39-7.37$ (d, $\left.J=10 \mathrm{~Hz}, 4 \mathrm{H}, 4-\mathrm{NP}\right), 6.29$ (s, 1H, $\left.\mathrm{H}_{\mathrm{c}}\right), 4.51-4.43(\mathrm{~m}, 4 \mathrm{H}$, $\left.\mathrm{H}_{\mathrm{e}}\right), 4.02 \& 3.94$ (two s, $3 \mathrm{H}, \mathrm{H}_{\mathrm{d}}$ \& $\mathrm{H}_{\mathrm{d}^{\prime}}$ ), 3.11-3.06 (m, 2H, $\left.\mathrm{H}_{\mathrm{f}}\right), 2.96-2.90\left(\mathrm{~m}, 2 \mathrm{H}, \mathrm{H}_{\mathrm{f}}\right) \mathrm{ppm}$. 
4 TNB(Dox)(4-NP) (Scheme 1). To a solution of doxorubicin hydrochloride (26 mg, 0.044 mmol) in anhydrous dimethylformaldehyde $(2 \mathrm{~mL})$ was added $N, N$-diisopropylethylamine $(0.023$ $\mathrm{mL}, 0.13 \mathrm{mmol})$ and TNB(4-NP) $(75 \mathrm{mg}, 0.11 \mathrm{mmol})$ in dimethylformaldehyde $(1 \mathrm{~mL})$. The mixture was stirred at room temp for $5 \mathrm{~h}$, and dimethylformaldehyde was removed under reduced pressure. The crude product was purified by flash column chromatography by eluting with 3\% methanol/chloroform. The desired product was obtained as red solid (45 mg, 93\%). TLC (3\% methanol/chloroform): $R_{f}=0.38$. MS (ESI) $\mathrm{m} / z$ (relative intensity, \%): calcd 1106.21 for $\mathrm{C}_{48} \mathrm{H}_{49} \mathrm{~N}_{3} \mathrm{NaO}_{22} \mathrm{~S}_{2}[\mathrm{M}+\mathrm{Na}]^{+}$; found 1106.0 (100). HRMS (ESI): calcd 1106.2141 for [M + $\mathrm{Na}]^{+}$, found 1106.2134. ${ }^{1} \mathrm{H}$ NMR (500 MHz, $\left.\mathrm{CDCl}_{3}\right): 8.28-8.26$ (m, 2H, 4-NP), 8.05-8.03 (d, $J=$ $10 \mathrm{~Hz}, 1 \mathrm{H}$, Dox-2), 7.81-7.77 (t, $J=10 \mathrm{~Hz}, 1 \mathrm{H}, \mathrm{Dox}-3), 7.46$ (s, 1H, $\left.\mathrm{H}_{\mathrm{a}}\right), 7.41-7.37$ (m, 4H, $\mathrm{H}_{\mathrm{b}}$ ), Dox-1 and 4-NP), 6.24 (s, 1H, $\mathrm{H}_{\mathrm{c}}$ ), 5.52-5.48 (m, 1H, Dox-1', 4.76 (s, 2H, Dox-14), 4.52-4.44 (m, 2H, $\mathrm{H}_{\mathrm{e}}$ ), 4.32-4.10 (m, 4H, Dox-4', Dox-5', $\mathrm{H}_{\mathrm{e}}$ ), 4.08 (s, 3H, Dox-OCH $), 3.99$ \& 3.93 (two $\left.\mathrm{s}, 6 \mathrm{H}, \mathrm{H}_{\mathrm{d}} \& \mathrm{H}_{\mathrm{d}^{\prime}}\right), 3.84-3.82(\mathrm{~m}, 1 \mathrm{H}$, Dox-3'), 3.68-3.66 (d, $J=10,1 \mathrm{H}$, Dox-7), 3.32-3.26 (m, 1H, Dox-10), 3.06-3.02 (m, 1H, Dox-10), 3.10-2.60 (m, 4H, H $\mathrm{H}_{\mathrm{f}}, 2.38-2.33$ (m, 1H, Dox-8), 2.18-2.12 (m, 1H, Dox-8), 1.88-1.72 (m, 2H, Dox-2'), 1.31-1.25 (m, 3H, Dox-6') ppm. ${ }^{13} \mathrm{C}$ NMR $\left(100 \mathrm{MHz}, \mathrm{CDCl}_{3}\right): 213.86,187.08,186.69,161.06,156.21,155.01,153.63,152.37$, $148.53,145.48,140.23,135.50,133.63,130.03,125.31,121.82,120.88,119.85,111.57,107.65$ $100.76,69.57,69.24,67.55,67.33,65.54,64.90,56.68,47.50,47.11,35.62,34.00,31.92,31.23$, 29.94, $16.92 \mathrm{ppm}$.

5 TNB(Dox)(NHBoc) (Scheme 1). To a cold solution of $3(56 \mathrm{mg}, 5.17 \mu \mathrm{mol})$ in $1.0 \mathrm{~mL}$ of anhydrous tetrahydrofuran was added a solution of $N$-Boc ethylenediamine $(13.2 \mathrm{mg})$ and triethylamine $(0.0345 \mathrm{~mL})$ dissolved in tetrahydrofuran $(0.5 \mathrm{~mL})$ in an ice bath $\left(\sim 5{ }^{\circ} \mathrm{C}\right)$. The mixture was stirred at $5{ }^{\circ} \mathrm{C}$ for $1 \mathrm{~h}$, and at room temp for $6 \mathrm{~h}$. After the reaction, the mixture was 
diluted with ethyl acetate $(6 \mathrm{~mL})$, and washed multiple times with a brine solution, $0.5 \mathrm{M} \mathrm{HCl}(5$ $\mathrm{mL}$ ), and a brine solution. After drying over sodium sulfate, the solution was concentrated in vacuo, and the crude product was purified by silica column chromatography by eluting with ethyl acetate/hexane (1:2 to $1: 1)$. TNB(4-NP)(NHBoc) was obtained as a pale yellow syrup (24 mg, 41\%). TLC (1:1 ethyl acetate/hexane): $R_{f}=0.28 .{ }^{1} \mathrm{H}$ NMR $\left(500 \mathrm{MHz}, \mathrm{CDCl}_{3}\right): 8.29-8.27$ (d, $J=10 \mathrm{~Hz}, 2 \mathrm{H}, 4-\mathrm{NP}), 7.49\left(\mathrm{~s}, 1 \mathrm{H}, \mathrm{H}_{\mathrm{a}}\right), 7.43\left(\mathrm{~s}, 1 \mathrm{H}, \mathrm{H}_{\mathrm{b}}\right), 7.41-7.39$ (d, J=10 Hz, 2H, 4-NP), 6.27 $\left(\mathrm{s}, 1 \mathrm{H}, \mathrm{H}_{\mathrm{c}}\right), 4.50-4.47\left(\mathrm{t}, J=7.5 \mathrm{~Hz}, 2 \mathrm{H}, \mathrm{H}_{\mathrm{e}}\right), 4.28-4.22\left(\mathrm{~m}, 2 \mathrm{H}, \mathrm{H}_{\mathrm{e}}\right), 4.01 \& 3.94$ (two s, 3H, $\mathrm{H}_{\mathrm{d}} \&$ $\left.\mathrm{H}_{\mathrm{d}^{\prime}}\right), 3.29-3.24\left(\mathrm{~m}, 4 \mathrm{H}, 2 \mathrm{CH}_{2} \mathrm{~N}\right), 3.14-3.08\left(\mathrm{~m}, 1 \mathrm{H}, \mathrm{H}_{\mathrm{f}}\right), 2.97-2.85\left(\mathrm{~m}, 2 \mathrm{H}, \mathrm{H}_{\mathrm{f}}\right), 2.72-2.68(\mathrm{~m}, 1 \mathrm{H}$, $\left.\mathrm{H}_{\mathrm{f}^{\prime}}\right) \mathrm{ppm}$.

To a solution of TNB(4-NP)(NHBoc) $(24 \mathrm{mg}, 0.034 \mathrm{mmol})$ in dimethylformaldehyde (1.0 $\mathrm{mL})$ was added doxorubicin hydrochloride $(21 \mathrm{mg}, 0.036 \mathrm{mmol})$ and triethylamine $(0.011 \mathrm{~mL}$, $0.082 \mathrm{mmol}$ ). The mixture was stirred at room temp in the dark overnight, and concentrated to $0.5 \mathrm{~mL}$. This solution was diluted with ethyl acetate $(10 \mathrm{~mL})$, and washed multiple times with brine, $0.5 \mathrm{M} \mathrm{HCl}$, and a saturated sodium bicarbonate solution, and brine. The organic layer was dried over sodium sulfate, concentrated in vacuo, and the residue was purified by silica column chromatography by eluting with 1 to $3 \%$ methanol in dichloromethane. The desired product 5 was obtained as a red solid (17 mg, 45\%). TLC (5\% methanol/dichloromethane): $R_{f}=0.37 . \mathrm{MS}$ (ESI) $m / z$ (relative intensity, \%) $=1127.3(100)[\mathrm{M}+\mathrm{Na}]^{+}$. HRMS (ESI) calcd for $\mathrm{C}_{49} \mathrm{H}_{60} \mathrm{~N}_{4} \mathrm{NaO}_{21} \mathrm{~S}_{2}[\mathrm{M}+\mathrm{Na}]^{+}$1127.3089, found 1127.3072. ${ }^{1} \mathrm{H}$ NMR (500 MHz, $\left.\mathrm{CDCl}_{3}\right): 8.06-$ $8.04(\mathrm{~d}, J=10 \mathrm{~Hz}, 1 \mathrm{H}$, Dox-2), 7.81-7.78 (t, $J=8 \mathrm{~Hz}, 1 \mathrm{H}, \mathrm{Dox}-3), 7.44\left(\mathrm{~s}, 1 \mathrm{H}, \mathrm{H}_{\mathrm{a}}\right), 7.43$ (s, 1H, $\left.\mathrm{H}_{\mathrm{b}}\right), 7.41-7.39\left(\mathrm{~d}, J=10 \mathrm{~Hz}, 1 \mathrm{H}\right.$, Dox-1), 6.26 and $6.22\left(\mathrm{~s}, 1 \mathrm{H}, \mathrm{H}_{\mathrm{c}}\right), 5.54(\mathrm{~s}, 1 \mathrm{H}$, Dox-1'), $4.78(\mathrm{~s}$, 2H, Dox-14), 4.40-4.13 (m, 5H, Dox-4', Dox-5', He), 4.09 (s, 3H, Dox-OCH H $^{\prime}$, 3.98 \& 3.93 (two s, $\left.6 \mathrm{H}, \mathrm{H}_{\mathrm{d}} \& \mathrm{H}_{\mathrm{d}^{\prime}}\right), 3.88$ (m, Dox-3', $\mathrm{H}_{\mathrm{e}^{\prime}}$ ), 3.79-3.75 (m, 1H, Dox-7), 3.33-3.28 (m, 1H, Dox-10), 3.29- 
$3.22\left(\mathrm{~m}, 4 \mathrm{H}, 2 \mathrm{CH}_{2} \mathrm{~N}\right), 3.07-3.04(\mathrm{~m}, 1 \mathrm{H}, \mathrm{Dox}-10), 2.98-2.56\left(\mathrm{~m}, 4 \mathrm{H}, \mathrm{H}_{\mathrm{f}}, \mathrm{H}_{\mathrm{f}}{ }^{\prime}\right), 2.40-2.37(\mathrm{~m}, 1 \mathrm{H}$, Dox-8), 2.18-2.14 (m, 1H, Dox-8), 2.00-1.81 (m, 2H, Dox-2'), 1.43 (s, 9H, 3CH $(N-B o c)), 1.34-$ 1.32 (m, 3H, Dox-6') ppm. ${ }^{13} \mathrm{C}$ NMR (500 MHz, $\mathrm{CDCl}_{3}$ ): 187.13, 186.74, 161.05, 156.32, 155.75, $155.33,135.73,133.71,119.85,118.39,111.62,111.53,107.40,100.94,92.61,69.12,67.44$, $65.59,64.19,56.68,56.58,56.42,47.29,46.92,41.33,40.40,35.65,33.95,31.76,31.64,31.24$, 29.96, 28.37, $17.00 \mathrm{ppm}$.

9 G5(FA) $)_{\mathbf{n}=5.4}(\text { Dox })_{m=5.1}$ (Scheme 2). This conjugate was prepared by an EDC-based amide conjugation of 8 G5(glutaric acid) ${ }^{5}$ with 6 and was characterized as detailed in Supporting Information.

11-12 UCN-PPUX@(Dox)(G5FA) (Figure 3). Details for 10 preparation $^{36}$ and its conjugation with 3 and G5(FA) 6 are described in Supporting Information.

Drug Release Kinetics. Studies of drug release controlled by long UV were performed using a Spectroline ${ }^{\circledR}$ UV lamp (XX-15A; peak intensity of emission at $365 \mathrm{~nm}$ ) as reported by our laboratories. ${ }^{5,40,43}$ In a representative experiment, 4 was dissolved in 20\% aqueous methanol (9.1 $\times 10^{-5} \mathrm{M}$ ), and exposed to the light at a distance of $5 \mathrm{~cm}$. A series of aliquots were collected as a function of irradiation time $(\mathrm{t}=0-15 \mathrm{~min})$, and analyzed by UPLC and UV-vis spectrophotometry in combination with high resolution mass spectroscopy which was employed to confirm the identities of release species. NIR-controlled release studies were performed in solutions and $\mathrm{KB}$ cells in vitro using a NIR laser $(980 \mathrm{~nm}$, power output $=1 \mathrm{~W}$; CNI Optoelectronics Tech) following the methods reported from our laboratories. ${ }^{36,40}$

Cell Culture: KB cells (human carcinoma) and B16 cells (mouse melanoma) were obtained from ATCC. KB cells were grown and maintained in KB media: RPMI 1640 media without folic acid (Gibco), supplemented with 10\% heat-inactivated fetal bovine serum (Gemini), and 100 
$\mathrm{U} / \mathrm{mL}$ penicillin/100 $\mu \mathrm{g} / \mathrm{mL}$ streptomycin (Gibco). B16 cells were grown in B16 media which was the same as KB media with folic acid.

In Vitro Cytotoxicity: For cell viability assays, KB cells were seeded for 2 days in 96-well tissue culture plates at a density of 3000 cells/well. Test compounds: TNB(Dox), dendrimers, and UCNs were made as solutions or suspensions (UCNs) in PBS from powder and sonicated in a bath sonicator for $30 \mathrm{~s}$ prior to dilution in media. Media was then removed from the cells, and replaced with the test compounds diluted in $\mathrm{KB}$ media at the indicated concentrations and incubated at $37{ }^{\circ} \mathrm{C}$ for $30 \mathrm{~min}$. For +UVA samples, cells were exposed to UVA irradiation by placing the plate directly under the same UV lamp used above for $10 \mathrm{~min}$. For no UVA samples, cells were left at room temperature for $10 \mathrm{~min}$ in the dark. Following irradiation, cells were incubated for $24 \mathrm{~h}$ at $37^{\circ} \mathrm{C}$. The next day, the compound was removed and replaced with fresh KB media. Cells were incubated for an additional 4 days and the viability was measured using an XTT assay kit (Roche) according to the manufacturer's protocol. For NIR induced cytotoxicity, $\mathrm{KB}$ cells were seeded for overnight in 96-well tissue culture plates at a density of 6000 cells/well. Growth media was removed, and UCN solutions were added to at the indicated concentrations $\mathrm{n} \mathrm{KB}$ media in a volume of $50 \mu \mathrm{L}$. Cells were incubated at $37^{\circ} \mathrm{C}$ for $30 \mathrm{~min}$, and then exposed to NIR $(980 \mathrm{~nm})$ through a fiber optic as described previously ${ }^{40}$ for $1 \mathrm{~h}$, or left in the dark at room temp for $1 \mathrm{~h}$. KB media $(150 \mu \mathrm{L})$ was added to each well resulting in a 1:4 dilution, and cells were then incubated for $24 \mathrm{~h}$ at $37^{\circ} \mathrm{C}$. All concentrations are expressed as the initial concentration of UCN. The following day, cells were rinsed with PBS, and fresh media was added. Cells were incubated for an additional 4 days at $37^{\circ} \mathrm{C}$ and the viability was measured as above by XTT. 
Confocal Microscopy: KB or B16 cells were seeded on an 8-well chambered tissue culture coverglass slide at a density of $0.5 \times 10^{6}$ cells/well in KB or B16 media overnight. Media was removed and replaced with solutions of $500 \mu \mathrm{g} / \mathrm{mL}$ UCNs $\mathbf{1 1}$ or $\mathbf{1 2}$ in the respective cell culture media. Cells were incubated at $37^{\circ} \mathrm{C}$ for $2 \mathrm{~h}$, after which the incubation media was aspirated and the cells were washed twice with PBS. Cells were then fixed in 4\% paraformaldehyde for 10 min, and mounted in Prolong Gold@ with DAPI (Life Technologies). Confocal images were acquired on a Leica inverted confocal microscope (Leica SP5X) at $\lambda_{\text {ex }}=980 \mathrm{~nm} ; \lambda_{\text {em }}=550 \mathrm{~nm}$, $650 \mathrm{~nm}$ for imaging the UCN core by NIR luminescence.

Flow Cytometry: For flow analysis, KB cells were trypsinized prior to the experiment, to give a suspension in $\mathrm{KB}$ media. These cells $\left(2 \times 10^{5}\right)$ were incubated with the indicated concentrations of Cy5 labeled UCN conjugates in a total volume of $250 \mu \mathrm{L}$ for $1 \mathrm{~h}$ at $37^{\circ} \mathrm{C}$ with periodic mixing. After the incubation, cells were spun down and washed twice with FACS buffer ( $0.1 \%$ BSA, PBS, $0.1 \%$ sodium azide). After the final wash, cells were resuspended in $100 \mu \mathrm{L}$ of FACS buffer, and analyzed by flow cytometry on a BD Accuri flow cytometer. The fluorescence in FL4 for Cy5 on samples gated for live cells were analyzed, and the \% of fluorescent cells was taken as the $\%$ of cells with fluorescence above that of untreated cells. Similar procedures were followed for FA competition studies, except $\mathrm{KB}$ cells were preincubated in $50 \mu \mathrm{M}$ or $1 \mathrm{mM}$ for 15 min at $37^{\circ} \mathrm{C}$ prior to addition of the UCNs, and FA was maintained in the incubation medium during the incubation with UCNs.

Supporting Information. The Supporting Information is available free of charge via the Internet at http://pubs.acs.org. Details for the synthesis and characterization of dendrimer and UCN nanoconjugates, and their spectral copies.

Notes. The authors declare no competing financial interest. 
Acknowledgements. This work was supported in part by the British Council and Department for Business Innovation \& Skills through the Global Innovation Initiative (GII 207).

\section{References}

(1) Farokhzad, O. C., Langer, R. (2009) Impact of Nanotechnology on Drug Delivery. ACS Nano $3,16-20$.

(2) Majoros, I. J., Williams, C. R., Becker, A., Baker Jr, J. R. (2009) Methotrexate Delivery via Folate Targeted Dendrimer-Based Nanotherapeutic Platform. Wiley Interdiscip. Rev.: Nanomed. Nanobiotechnol. 1, 502-510.

(3) Tomalia, D. A., Naylor, A. M., William A. Goddard, I. (1990) Starburst Dendrimers: Molecular-Level Control of Size, Shape, Surface Chemistry, Topology, and Flexibility from Atoms to Macroscopic Matter. Angew. Chem., Int. Ed. 29, 138-175.

(4) Agasti, S. S., Chompoosor, A., You, C.-C., Ghosh, P., Kim, C. K., Rotello, V. M. (2009) Photoregulated Release of Caged Anticancer Drugs from Gold Nanoparticles. J. Am. Chem. Soc. $131,5728-5729$.

(5) Choi, S. K., Thomas, T., Li, M., Kotlyar, A., Desai, A., Baker Jr, J. R. (2010) LightControlled Release of Caged Doxorubicin from Folate Receptor-Targeting PAMAM Dendrimer Nanoconjugate. Chem. Commun. (Cambridge, U. K.) 46, 2632-2634.

(6) Dcona, M. M., Yu, Q., Capobianco, J. A., Hartman, M. C. T. (2015) Near infrared light mediated release of doxorubicin using upconversion nanoparticles. Chem. Commun. (Cambridge, U. K.) 51, 8477-8479.

(7) Zhang, Y., Thomas, T. P., Desai, A., Zong, H., Leroueil, P. R., Majoros, I. J., Baker, J. R. (2010) Targeted Dendrimeric Anticancer Prodrug: A Methotrexate-Folic AcidPoly(amidoamine) Conjugate and a Novel, Rapid, "One Pot” Synthetic Approach. Bioconjugate Chem. 21, 489-495. 
(8) Duncan, B., Li, X., Landis, R. F., Kim, S. T., Gupta, A., Wang, L.-S., Ramanathan, R., Tang, R., Boerth, J. A., Rotello, V. M. (2015) Nanoparticle-Stabilized Capsules for the Treatment of Bacterial Biofilms. ACS Nano 9, 7775-7782.

(9) Gu, H., Ho, P.-L., Tsang, K. W. T., Wang, L., Xu, B. (2003) Using Biofunctional Magnetic Nanoparticles to Capture Vancomycin-Resistant Enterococci and Other Gram-Positive Bacteria at Ultralow Concentration. J. Am. Chem. Soc. 125, 15702-15703.

(10) Kell, A. J., Stewart, G., Ryan, S., Peytavi, R., Boissinot, M., Huletsky, A., Bergeron, M. G., Simard, B. (2008) Vancomycin-Modified Nanoparticles for Efficient Targeting and Preconcentration of Gram-Positive and Gram-Negative Bacteria. ACS Nano 2, 1777-1788.

(11) Wong, P., Tang, S., Mukherjee, J., Tang, K., Gam, K., Isham, D., Murat, C., Sun, R., Baker, J. R., Choi, S. K. (2016) Light-Controlled Active Release of Photocaged Ciprofloxacin for Lipopolysaccharide-Targeted Drug Delivery using Dendrimer Conjugates. Chem. Commun. (Cambridge, U. K.) 52, 10357-10360.

(12) Metallo, S. J., Kane, R. S., Holmlin, R. E., Whitesides, G. M. (2003) Using Bifunctional Polymers Presenting Vancomycin and Fluorescein Groups To Direct Anti-Fluorescein Antibodies to Self-Assembled Monolayers Presenting d-Alanine-d-Alanine Groups. J. Am. Chem. Soc. 125, 4534-4540.

(13) Liu, J., Zhou, J., Luo, Y. (2012) SiRNA Delivery Systems Based on Neutral Cross-Linked Dendrimers. Bioconjugate Chem. 23, 174-183.

(14) Tang, Y., Li, Y.-B., Wang, B., Lin, R.-Y., van Dongen, M., Zurcher, D. M., Gu, X.-Y., Banaszak Holl, M. M., Liu, G., Qi, R. (2012) Efficient in Vitro siRNA Delivery and Intramuscular Gene Silencing Using PEG-Modified PAMAM Dendrimers. Mol. Pharmaceutics 9, 1812-1821.

(15) Kong, L., Alves, C. S., Hou, W., Qiu, J., Möhwald, H., Tomás, H., Shi, X. (2015) RGD Peptide-Modified Dendrimer-Entrapped Gold Nanoparticles Enable Highly Efficient and Specific Gene Delivery to Stem Cells. ACS Appl. Mater. Interfaces 7, 4833-4843. 
(16) Han, G., You, C.-C., Kim, B.-j., Turingan, R. S., Forbes, N. S., Martin, C. T., Rotello, V. M. (2006) Light-Regulated Release of DNA and Its Delivery to Nuclei by Means of Photolabile Gold Nanoparticles. Angew. Chem., Int. Ed. 45, 3165-3169.

(17) Cai, H., Li, K., Li, J., Wen, S., Chen, Q., Shen, M., Zheng, L., Zhang, G., Shi, X. (2015) Dendrimer-Assisted Formation of $\mathrm{Fe}_{3} \mathrm{O}_{4} / \mathrm{Au}$ Nanocomposite Particles for Targeted Dual Mode CT/MR Imaging of Tumors. Small 11, 4584-4593.

(18) Shi, X., Wang, S. H., Swanson, S. D., Ge, S., Cao, Z., Antwerp, M. E. V., Landmark, K. J., Baker Jr., J. R. (2008) Dendrimer-Functionalized Shell-crosslinked Iron Oxide Nanoparticles for In-Vivo Magnetic Resonance Imaging of Tumors. Adv. Mater. (Weinheim, Ger.) 20, 1671-1678.

(19) Kim, S. T., Saha, K., Kim, C., Rotello, V. M. (2013) The Role of Surface Functionality in Determining Nanoparticle Cytotoxicity. Acc. Chem. Res. 46, 681-691.

(20) Mu, Q., Jiang, G., Chen, L., Zhou, H., Fourches, D., Tropsha, A., Yan, B. (2014) Chemical Basis of Interactions Between Engineered Nanoparticles and Biological Systems. Chem. Rev. (Washington, DC, U. S.) 114, 7740-7781.

(21) Guo, Y., Sakonsinsiri, C., Nehlmeier, I., Fascione, M. A., Zhang, H., Wang, W., Pöhlmann, S., Turnbull, W. B., Zhou, D. (2016) Compact, Polyvalent Mannose Quantum Dots as Sensitive, Ratiometric FRET Probes for Multivalent Protein-Ligand Interactions. Angew. Chem., Int. Ed. $55,4738-4742$.

(22) Li, M.-H., Choi, S. K., Leroueil, P. R., Baker, J. R. (2014) Evaluating Binding Avidities of Populations of Heterogeneous Multivalent Ligand-Functionalized Nanoparticles. ACS Nano 8, $5600-5609$.

(23) Mammen, M., Choi, S. K., Whitesides, G. M. (1998) Polyvalent Interactions in Biological Systems: Implications for Design and Use of Multivalent Ligands and Inhibitors. Angew. Chem., Int. Ed. 37, 2754-2794.

(24) Smith, B. A., Smith, B. D. (2012) Biomarkers and Molecular Probes for Cell Death Imaging and Targeted Therapeutics. Bioconjugate Chem. 23, 1989-2006. 
(25) Zhou, H., Jiao, P., Yang, L., Li, X., Yan, B. (2010) Enhancing Cell Recognition by Scrutinizing Cell Surfaces with a Nanoparticle Array. J. Am. Chem. Soc. 133, 680-682.

(26) Wong, P. T., Choi, S. K. (2015) Mechanisms of Drug Release in Nanotherapeutic Delivery Systems. Chem. Rev. (Washington, DC, U. S.) 115, 3388-3432.

(27) Lin, Q., Huang, Q., Li, C., Bao, C., Liu, Z., Li, F., Zhu, L. (2010) Anticancer Drug Release from a Mesoporous Silica Based Nanophotocage Regulated by Either a One- or Two-Photon Process. J. Am. Chem. Soc. 132, 10645-10647.

(28) Dvir, T., Banghart, M. R., Timko, B. P., Langer, R., Kohane, D. S. (2009) Photo-Targeted Nanoparticles. Nano Lett. 10, 250-254.

(29) Ojima, I., Geng, X., Wu, X., Qu, C., Borella, C. P., Xie, H., Wilhelm, S. D., Leece, B. A., Bartle, L. M., Goldmacher, V. S., et al. (2002) Tumor-Specific Novel Taxoid-Monoclonal Antibody Conjugates. J. Med. Chem. 45, 5620-5623.

(30) Kukowska-Latallo, J. F., Candido, K. A., Cao, Z., Nigavekar, S. S., Majoros, I. J., Thomas, T. P., Balogh, L. P., Khan, M. K., Baker Jr, J. R. (2005) Nanoparticle Targeting of Anticancer Drug Improves Therapeutic Response in Animal Model of Human Epithelial Cancer. Cancer Res. 65, 5317-5324.

(31) Son, Y. J., Jang, J.-S., Cho, Y. W., Chung, H., Park, R.-W., Kwon, I. C., Kim, I.-S., Park, J. Y., Seo, S. B., Park, C. R., et al. (2003) Biodistribution and anti-tumor efficacy of doxorubicin loaded glycol-chitosan nanoaggregates by EPR effect. J. Controlled Release 91, 135-145.

(32) Bae, Y., Nishiyama, N., Fukushima, S., Koyama, H., Yasuhiro, M., Kataoka, K. (2005) Preparation and Biological Characterization of Polymeric Micelle Drug Carriers with Intracellular pH-Triggered Drug Release Property: Tumor Permeability, Controlled Subcellular Drug Distribution, and Enhanced in Vivo Antitumor Efficacy. Bioconjugate Chem. 16, 122-130.

(33) Chau, Y., Tan, F. E., Langer, R. (2004) Synthesis and Characterization of Dextran-Peptide-Methotrexate Conjugates for Tumor Targeting via Mediation by Matrix Metalloproteinase II and Matrix Metalloproteinase IX. Bioconjugate Chem. 15, 931-941. 
(34) Gullotti, E., Yeo, Y. (2009) Extracellularly Activated Nanocarriers: A New Paradigm of Tumor Targeted Drug Delivery. Mol. Pharmaceutics 6, 1041-1051.

(35) Huang, B., Tang, S., Desai, A., Cheng, X.-m., Kotlyar, A., Spek, A. V. D., Thomas, T. P., Baker Jr, J. R. (2009) Human plasma-mediated hypoxic activation of indolequinone-based naloxone pro-drugs. Bioorg. Med. Chem. Lett. 19, 5016-5020.

(36) Chen, D., Tao, R., Tao, K., Chen, B., Choi, S. K., Tian, Q., Xu, Y., Zhou, G., Sun, K. (2017) Efficacy Dependence of Photodynamic Therapy Mediated by Upconversion Nanoparticles: Subcellular Positioning and Irradiation Productivity. Small 13, 1602053.

(37) Riedinger, A., Guardia, P., Curcio, A., Garcia, M. A., Cingolani, R., Manna, L., Pellegrino, T. (2013) Subnanometer Local Temperature Probing and Remotely Controlled Drug Release Based on Azo-Functionalized Iron Oxide Nanoparticles. Nano Lett. 13, 2399-2406.

(38) Poon, L., Zandberg, W., Hsiao, D., Erno, Z., Sen, D., Gates, B. D., Branda, N. R. (2010) Photothermal Release of Single-Stranded DNA from the Surface of Gold Nanoparticles Through Controlled Denaturating and $\mathrm{Au}-\mathrm{S}$ Bond Breaking. ACS Nano 4, 6395-6403.

(39) Xu, F., Hu, M., Liu, C., Choi, S. K. (2017) Yolk-structured multifunctional up-conversion nanoparticles for synergistic photodynamic-sonodynamic antibacterial resistance therapy. Biomater. Sci. 5, 678-685.

(40) Wong, P. T., Chen, D., Tang, S., Yanik, S., Payne, M., Mukherjee, J., Coulter, A., Tang, K., Tao, K., Sun, K., et al. (2015) Modular Integration of Upconversion Nanocrystal-Dendrimer Composites for Folate Receptor-Specific Near Infrared Imaging and Light Triggered Drug Release. Small 11, 6078-6090.

(41) Chien, Y.-H., Chou, Y.-L., Wang, S.-W., Hung, S.-T., Liau, M.-C., Chao, Y.-J., Su, C.-H., Yeh, C.-S. (2013) Near-Infrared Light Photocontrolled Targeting, Bioimaging, and Chemotherapy with Caged Upconversion Nanoparticles in Vitro and in Vivo. ACS Nano 7, 8516-8528.

(42) Hamblin, M. R., Hasan, T. (2004) Photodynamic therapy: a new antimicrobial approach to infectious disease? Photochem. Photobiol. Sci. 3, 436-450. 
(43) Wong, P. T., Roberts, E. W., Tang, S., Mukherjee, J., Cannon, J., Nip, A. J., Corbin, K., Krummel, M. F., Choi, S. K. (2017) Control of an Unusual Photo-Claisen Rearrangement in Coumarin Caged Tamoxifen through an Extended Spacer. ACS Chem. Biol. 12, 1001-1010.

(44) Klán, P., Šolomek, T., Bochet, C. G., Blanc, A., Givens, R., Rubina, M., Popik, V., Kostikov, A., Wirz, J. (2012) Photoremovable Protecting Groups in Chemistry and Biology: Reaction Mechanisms and Efficacy. Chem. Rev. (Washington, DC, U. S.) 113, 119-191.

(45) Lin, Q., Bao, C., Yang, Y., Liang, Q., Zhang, D., Cheng, S., Zhu, L. (2013) Highly Discriminating Photorelease of Anticancer Drugs Based on Hypoxia Activatable Phototrigger Conjugated Chitosan Nanoparticles. Adv. Mater. (Weinheim, Ger.) 25, 1981-1986.

(46) Choi, S. K., Verma, M., Silpe, J., Moody, R. E., Tang, K., Hanson, J. J., Baker Jr, J. R. (2012) A photochemical approach for controlled drug release in targeted drug delivery. Bioorg. Med. Chem. 20, 1281-1290.

(47) Johnson, J. A., Lu, Y. Y., Burts, A. O., Lim, Y.-H., Finn, M. G., Koberstein, J. T., Turro, N. J., Tirrell, D. A., Grubbs, R. H. (2011) Core-Clickable PEG-Branch-Azide Bivalent-Bottle-Brush Polymers by ROMP: Grafting-Through and Clicking-To. J. Am. Chem. Soc. 133, 559-566.

(48) Wong, P. T., Tang, S., Cannon, J., Mukherjee, J., Isham, D., Gam, K., Payne, M., Yanik, S. A., Baker, J. R., Choi, S. K. (2017) A Thioacetal Photocage Designed for Dual Release: Application in the Quantitation of Therapeutic Release by Synchronous Reporter Decaging. ChemBioChem 18, 126-135.

(49) Hu, X., Tian, J., Liu, T., Zhang, G., Liu, S. (2013) Photo-Triggered Release of Caged Camptothecin Prodrugs from Dually Responsive Shell Cross-Linked Micelles. Macromolecules $46,6243-6256$.

(50) Alam, S., Alves, D. S., Whitehead, S. A., Bayer, A. M., McNitt, C. D., Popik, V. V., Barrera, F. N., Best, M. D. (2015) A Clickable and Photocleavable Lipid Analogue for Cell Membrane Delivery and Release. Bioconjugate Chem. 26, 1021-1031. 
(51) Idris, N. M., Jayakumar, M. K. G., Bansal, A., Zhang, Y. (2015) Upconversion nanoparticles as versatile light nanotransducers for photoactivation applications. Chem. Soc. Rev. $44,1449-1478$.

(52) Anderson, R. R., Parrish, J. A. (1981) The Optics of Human Skin. J. Invest. Dermatol. 77, 13-19.

(53) Liu, Q., Feng, W., Yang, T., Yi, T., Li, F. (2013) Upconversion luminescence imaging of cells and small animals. Nat. Protoc. 8, 2033-2044.

(54) Mullen, D. G., Fang, M., Desai, A., Baker Jr, J. R., Orr, B. G., Banaszak Holl, M. M. (2010) A Quantitative Assessment of Nanoparticle-Ligand Distributions: Implications for Targeted Drug and Imaging Delivery in Dendrimer Conjugates. ACS Nano 4, 657-670.

(55) Low, P. S., Henne, W. A., Doorneweerd, D. D. (2008) Discovery and Development of Folic-Acid-Based Receptor Targeting for Imaging and Therapy of Cancer and Inflammatory Diseases. Acc. Chem. Res. 41, 120-129.

(56) Chen, B., Le, W., Wang, Y., Li, Z., Wang, D., Ren, L., Lin, L., Cui, S., Hu, J. J., Hu, Y., et al. (2016) Targeting Negative Surface Charges of Cancer Cells by Multifunctional Nanoprobes. Theranostics 6, 1887-1898.

(57) Venkatesh, Y., Rajesh, Y., Karthik, S., Chetan, A. C., Mandal, M., Jana, A., Singh, N. D. P. (2016) Photocaging of Single and Dual (Similar or Different) Carboxylic and Amino Acids by Acetyl Carbazole and its Application as Dual Drug Delivery in Cancer Therapy. J. Org. Chem. $81,11168-11175$.

(58) Gorka, A. P., Nani, R. R., Zhu, J., Mackem, S., Schnermann, M. J. (2014) A Near-IR Uncaging Strategy Based on Cyanine Photochemistry. J. Am. Chem. Soc. 136, 14153-14159. 
For Table of Contents Only
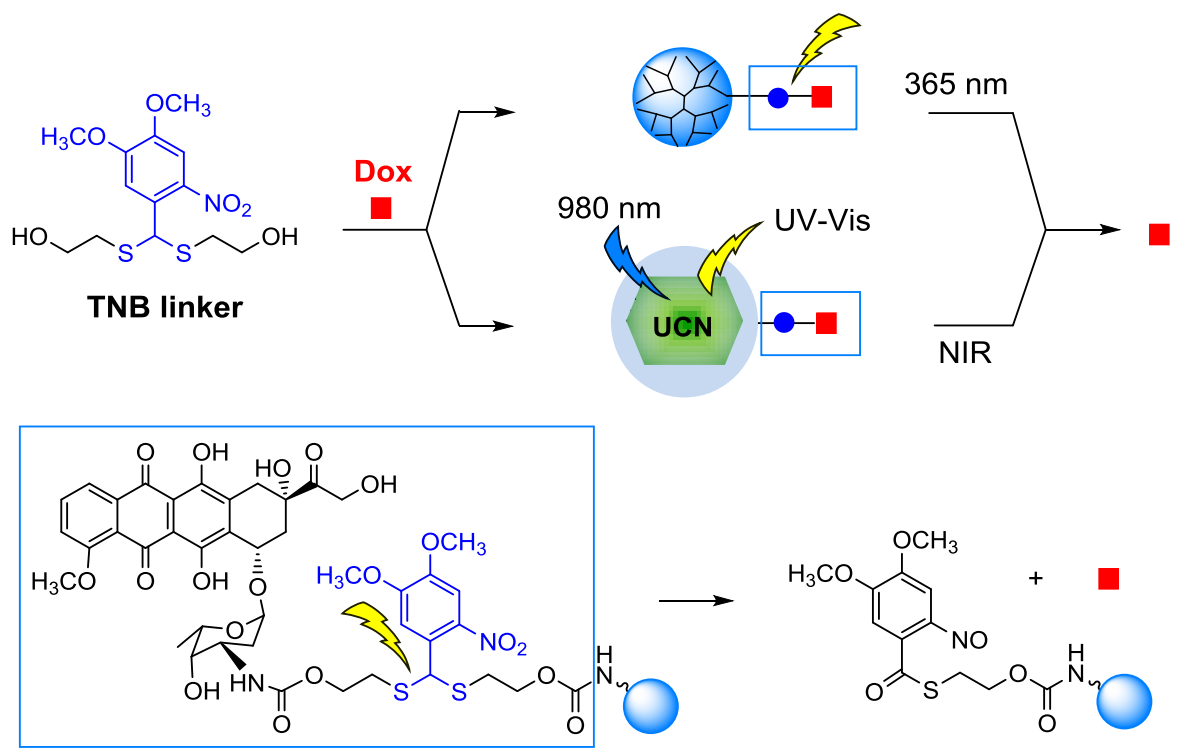


\section{SUPPORTING INFORMATION}

\section{Photocontrolled Release of Doxorubicin Conjugated through a Thioacetal Photocage in Folate-Targeted Nanodelivery Systems}

Pamela T. Wong, ${ }^{\dagger *}$ Shengzhuang Tang, ${ }^{\dagger, *}$ Jayme Cannon, ${ }^{\dagger+}$ Dexin Chen,${ }^{\S}$ Rachel Sun, ${ }^{\dagger}$ Jennifer Lee, ${ }^{\dagger}$ James Phan, ${ }^{\dagger}$ Ke Tao,${ }^{*,}$ Kang Sun, ${ }^{* \&}$ Biqiong Chen, James R. Baker, Jr., ${ }^{\prime, *}$ and Seok Ki Choi ${ }^{*}, \dot{t},{ }^{*}$

${ }^{\dagger}$ Michigan Nanotechnology Institute for Medicine and Biological Sciences, ${ }^{*}$ Department of Internal Medicine, University of Michigan Medical School, Ann Arbor, Michigan 48109, United States

${ }^{\S}$ State Key Laboratory of Metal Matrix Composites, School of Materials Science and Engineering, Shanghai Jiao Tong University, Shanghai 200240, People's Republic of China "School of Mechanical and Aerospace Engineering, Queen's University Belfast, Stranmillis Road, Belfast BT9 5AH, United Kingdom

${ }^{*}$ To whom correspondence should be addressed,

E-mail: ktao@sjtu.edu.cn

E-mail:ksun@sjtu.edu.cn

E-mail: skchoi@umich.edu

\section{Table of Contents}

1. Materials and Methods (page S2)

2. Synthesis of $\mathbf{9}$ G5(FA) $)_{5.4}(\text { Dox })_{5.1} \quad$ (page S3)

3. Synthesis of 12 UCN-PPIX@(Dox)(G5FA) （page S5)

4. Table S1 (page S9)

5. Figures S1, S2 (page S10)

6. Copies of Spectral Data $\left({ }^{1} \mathrm{H}\right.$ and ${ }^{13} \mathrm{C}$ NMR, HRMS, MALDI) (page S12)

7. References (page S16) 


\section{Materials and Methods}

\section{Materials}

Reagents and solvents were purchased from commercial suppliers and used as received. Those from Sigma-Aldrich include 4,5-dimethoxy-6-nitrobenzaldehyde (purity $\geq 98 \%$ ), 2mercaptoethanol ( $\geq 99 \%)$, folic acid dihydrate (98\%), 4-nitrophenyl chloroformate $(96 \%)$, and $N$ Boc ethylenediamine ( $\geq 98 \%)$. Doxorubicin hydrochloride $(98.0 \%)$ was purchased from AvaChem Scientific (San Antonio, TX). Poly(amidoamine) (PAMAM) dendrimer (Generation 5) $\mathrm{G} 5\left(\mathrm{NH}_{2}\right)_{n}$ (theoretical $\left.n=128\right)$ was purchased as a solution in methanol $(17.5 \% \mathrm{w} / \mathrm{w})$ from Dendritech, Inc. (Midland, MI). Prior to use, it was dialyzed against deionized water in a membrane tubing (MWCO $10 \mathrm{kDa}$ ), and its number of primary amine branches (experimental, $n$ $=114$ ) was determined by potentiometric titration as reported by our laboratories. ${ }^{1}$

Unless noted otherwise, each reaction for small molecule synthesis was carried out at an ambient temperature under a nitrogen atmosphere. Its progress was monitored routinely by thin layer chromatography (TLC) on $\operatorname{Merck}{ }^{\circledR}$ TLC plates $(250 \mu \mathrm{m}$ thick) and its product was detected through illumination with a UV lamp (254 or $365 \mathrm{~nm}$ ) and by staining with a phosphomolybdic acid reagent $(20 \% \mathrm{w} / \mathrm{v}$ in ethanol) and/or in an iodine chamber. Reaction products were purified by flash column chromatography using silica gel (200-400 mesh).

\section{Analytical Methods}

Compound homogeneity was assessed by ultraperformance liquid chromatography (UPLC $^{\mathrm{TM}}$, Waters) on an Acquity Peptide Mapping System equipped with a photodiode array detector as reported previously. ${ }^{2}$ Each UPLC sample was prepared in $30-50 \%$ aqueous acetonitrile at a concentration of $0.1-0.5 \mathrm{mg} \times \mathrm{mL}^{-1}$, and injected on a C4 BEH column $(100 \times$ 
$2.1 \mathrm{~mm}, 300 \AA$ ) at a flow rate of $0.2 \mathrm{~mL} \times \mathrm{min}^{-1}$. A linear gradient method was applied with a mixture of eluent A (0.1 TFA v/v\% in water) and eluent $\mathrm{B}(0.1 \mathrm{TFA} \mathrm{v} / \mathrm{v} \%$ in acetonitrile). It started with an initial gradient $1 \%$ B (0-1.4 min), followed by a linear increase to $80 \%$ B (1.4$13.4 \mathrm{~min})$, a linear decrease to $50 \% \mathrm{~B}(13.4-13.8 \mathrm{~min})$ and then to $1 \% \mathrm{~B}(13.8-14.4 \mathrm{~min})$ and ended with an isocratic condition $1 \% \mathrm{~B}$ (14.4-18 min).

NMR spectroscopy was performed in Varian NMR spectrometers at either $500 \mathrm{MHz}$ for ${ }^{1} \mathrm{H}$ nuclei or $100 \mathrm{MHz}$ for ${ }^{13} \mathrm{C}$ nuclei. Each NMR sample was prepared in deuterated solvents $\left(\mathrm{CDCl}_{3}, \mathrm{CD}_{3} \mathrm{OD}, \mathrm{DMSO}-d_{6}\right)$ at the concentration of $0.5-2.0 \mathrm{mg} / \mathrm{mL}$ as specified in the experimental section. Values of chemical shifts $(\delta)$ in the NMR spectra were recorded in a standard unit (ppm) relative to an internal reference compound $(\delta=0.00 \mathrm{ppm})$ such as tetramethylsilane (TMS) or 2,2-dimethyl-2-silapentane-5-sulfonate sodium salt (DSS), or were corrected with known reference values pertaining to residual solvent peaks.

UV-vis spectra were recorded in a Perkin Elmer Lambda 20 spectrophotometer. Mass spectrometry (ESI MS) for small molecules was performed in a Micromass AutoSpec Ultima spectrometer under either a positive or negative ionization mode. Molecular mass $\left(M_{\mathrm{r}}\right)$ of PAMAM dendrimer conjugates was characterized by matrix assisted laser desorption ionization time-of-flight mass spectrometry (MALDI-TOF MS) in a TOfsPec-2E spectrometer (Waters).

\section{Synthesis of 9 G5(FA) $)_{n=5.4}(\text { Dox })_{m=5.1}($ Scheme 2)}

$6 \mathrm{TNB}(\mathrm{Dox})\left(\mathbf{N H}_{2}\right)$. To a solution of $5 \mathrm{TNB}(\mathrm{Dox})(\mathrm{NHBoc})(6.9 \mathrm{mg}, 6.3 \mu \mathrm{mol})$ dissolved in anhydrous dichloromethane $(1 \mathrm{~mL})$ was added trifluoroacetic acid (TFA, $0.5 \mathrm{~mL})$. The mixture was stirred for $15 \mathrm{~min}$ at room temp and concentrated in vacuo. The product was used immediately without further purification in the next step as described below. 
9 G5(FA) $)_{\mathbf{n}=5.4}(\text { Dox })_{\mathbf{m}=5.1}$. To a suspension of 8 G5(Glutaric Acid $)^{3}\left(\mathrm{M}_{\mathrm{w}}=40,200 \mathrm{~g} \mathrm{~mol}^{-1} ; 20\right.$ $\mathrm{mg}, 0.498 \mu \mathrm{mol})$ in anhydrous DMF $(5 \mathrm{~mL})$ was added 4-dimethylaminopyridine $(6 \mathrm{mg}, 49.2$ $\mu \mathrm{mol}$ ), $N$-hydroxysuccinimide (NHS; $6 \mathrm{mg}, 52 \mu \mathrm{mol}$ ), and $N$-(3-dimethylaminopropyl)- $N^{\prime}-$ ethylcarbodiimide hydrochloride (EDC; $10 \mathrm{mg}, 52 \mu \mathrm{mol})$. This mixture was stirred at room temp for $36 \mathrm{~h}$ to preactivate each glutarate residue on the dendrimer surface to its NHS ester prior to the addition of a solution of DMF $(0.5 \mathrm{~mL})$ that contained a folic acid derivative ${ }^{4} \mathrm{FA}\left(\mathrm{NH}_{2}\right)(5$ mg, $10.0 \mu \mathrm{mol})$ and $6 \mathrm{TNB}(\mathrm{Dox})\left(\mathrm{NH}_{2}\right)$ (freshly prepared, $\left.6.3 \mu \mathrm{mol}\right)$. Then triethylamine $(27 \mu \mathrm{L}$, $194 \mu \mathrm{mol})$ was added to the reaction mixture to adjust its $\mathrm{pH}$ to be slightly basic (pH 9). The mixture was stirred at room temp for $36 \mathrm{~h}$ in the dark, and the conjugation reaction was quenched by adding water $(1 \mathrm{~mL})$. The mixture was concentrated to a volume of $\sim 1 \mathrm{~mL}$, and diluted with water $(8 \mathrm{~mL})$. The solution was concentrated in vacuo, and the residue was loaded into a membrane dialysis tubing (MWCO $10 \mathrm{kDa}$ ). The dialysis was performed extensively against deionized water $(2 \mathrm{~L})$, phosphate-buffered saline solution $(1 \mathrm{~L})$, and deionized water $(3 \times 2 \mathrm{~L})$ over $48 \mathrm{~h}$. The purified solution in the tubing was collected and lyophilized, yielding 9 G5(FA) $)_{\mathrm{n}}(\text { Dox })_{\mathrm{m}}$ as a brick red fluffy solid. UPLC analysis: $t_{\mathrm{R}}=8.3 \mathrm{~min}$ (polymer purity $\geq 95 \%$ ); UV-vis (PBS pH 7.4): $\lambda_{\max }=283\left(\varepsilon=251,878 \mathrm{M}^{-1} \mathrm{~cm}^{-1} ; \mathrm{FA}\right), 355\left(\varepsilon=94,280 \mathrm{M}^{-1} \mathrm{~cm}^{-1}\right.$; FA), $485\left(\varepsilon=60,421 \mathrm{M}^{-1} \mathrm{~cm}^{-1}\right.$; Dox $) \mathrm{nm}$. MALDI-TOF $(\mathrm{m} / \mathrm{z}): 47,400 \mathrm{~g} \mathrm{~mol}^{-1} .{ }^{1} \mathrm{H}$ NMR $(500 \mathrm{MHz}$, DMSO- $d_{6}$ ): $\delta 8.60$ (br s), 8.15-7.91 (strong; br m), 7.65-7.55 (br m), 7.25-7.10 (br m), 8.90 (br s), 6.60 (br s), 5.40 (br s), 5.10 (br s), 4.45 (br s), 4.20 (strong; br s), 4.00 (br s), 3.90 (br s), 3.80 (br s), 3.65 (br s), 3.40 (strong; br s), 3.07 (strong; br s), 2.93 (strong; br s), 2.75 (br s), 2.63 (strong; br s), 2.54 (strong; br s), 2.42 (strong; br s), 2.38 (br s), 2.18-2.04 (strong; br m), 1.80 (br s), 1.69 (strong; br s). *Acronyms: br (broad), s (singlet), m (multiplet). 
The number (valency) of $\operatorname{TNB}(\mathrm{Dox})(m=5.1 \pm 0.3)$ attached to $\mathrm{G} 5(\mathrm{FA})_{n}(\mathrm{Dox})_{m}$ was determined on an average basis according to Beer's law $(\mathrm{A}=\varepsilon \times 1 \times \mathrm{c})$. In this analysis, a standard calibration curve was generated for free Dox $\left([\mathrm{Dox}]=\left(5.74 \times 10^{-5}\right) \times A_{480} ; \mathrm{R}^{2}=0.993\right)$, and applied to calculate its valency as a molar ratio of $[$ Dox $] /[9](n=3)$. The ligand valency of FA $(n=5.4 \pm 1.3)$ was estimated by an NMR integration method in which the proton signal for FA at $\delta$ 6.8-7.0 ppm $(2 \mathrm{H})$ was compared to a reference group of $\mathrm{HNC}(=\mathrm{O}) \mathrm{CH}_{2} \mathbf{C H}_{2} \mathrm{CH}_{2} \mathrm{C}(=\mathrm{O})$ at $\delta 1.71 \mathrm{ppm}$ (108 glutarate residues per dendrimer $\left.{ }^{3}\right)$.

\section{Synthesis of UCN-PPIX@(Dox)(G5FA) (Figure 3)}

Upconversion Nanocrystal ( $\beta$-NaYF $\mathbf{4}: \mathbf{2 0} \%$ Yb, 2\%Er). UCN (NaYF $: 20 \% \mathrm{Yb}, 2 \% \mathrm{Er}$ ) was prepared by a hot injection method as reported earlier. ${ }^{4,5}$ In brief, a mixture of octadecene (10 $\mathrm{mL})$, oleic acid $(9.7 \mathrm{~mL})$ and sodium oleate $(288 \mathrm{mg})$ was heated at $290{ }^{\circ} \mathrm{C}$ and followed by a dropwise injection of a preheated $\left(100{ }^{\circ} \mathrm{C}\right)$ mixture of oleic acid $(2.5 \mathrm{~mL})$ and octadecene $(2.5$ $\mathrm{mL})$ that contained $\mathrm{CF}_{3} \mathrm{COONa}(350 \mathrm{mg}, 2.5 \mathrm{mmol}),\left(\mathrm{CF}_{3} \mathrm{COO}\right)_{3} \mathrm{Y}(333.8 \mathrm{mg}, 0.78 \mathrm{mmol})$, $\left(\mathrm{CF}_{3} \mathrm{COO}\right)_{3} \mathrm{Yb}(102 \mathrm{mg}, 0.2 \mathrm{mmol})$, and $\left(\mathrm{CF}_{3} \mathrm{COO}\right)_{3} \mathrm{Er}(10.2 \mathrm{mg}, 0.02 \mathrm{mmol})$ under dry nitrogen. After its injection, the final mixture was heated to $330^{\circ} \mathrm{C}$ and stirred further for $20 \mathrm{~min}$. To isolate the product, the hot mixture was cooled to room temp, and ethanol was added to precipitate formed UCNs. The desired $\mathrm{UCN}\left(\beta-\mathrm{NaYF}_{4}: 20 \% \mathrm{Yb}, 2 \% \mathrm{Er}\right)$ was collected by centrifugation and rinsed thoroughly with chloroform and methanol.

10 UCN-PPIX. Details for the preparation of UCN-PPIX are described recently in our report. ${ }^{6}$ The $\mathrm{UCN}\left(\mathrm{NaYF}_{4}: 20 \% \mathrm{Yb}, 2 \% \mathrm{Er}\right)($ mean diameter $=42 \mathrm{~nm})$ prepared above was coated with a siloxane polymer layer with $3-5 \mathrm{~nm}$ in thickness that contained protoporphyrin IX (PPIX) 
by a nonionic water-in-oil microemulsion method. This method led to the incorporation of PPIX at a composition rate of $3.27 \%(\mathrm{w} / \mathrm{w})$ in the shell layer of UCN-PPIX.

11 UCN-PPIX@(Dox). 4 TNB(Dox)(4-NP) (2.0 mg; $1.85 \mu \mathrm{mol})$ was dissolved in methanol $(1.0 \mathrm{~mL} ; 1.85 \mathrm{mM})$. An aliquot $(0.02 \mathrm{~mL})$ was taken from this solution, diluted with PBS pH 7.4 $(1.0 \mathrm{~mL})$, and labeled as "aliquot 1 ". This aliquot solution served as a reference to calculate the amount of TNB(Dox)(4-NP) that reacted with UCN-PPIX. The remaining solution $(0.98 \mathrm{~mL})$ was used next step as follows.

To UCN-PPIX $(20 \mathrm{mg})$ dispersed in acetonitrile $(1 \mathrm{~mL})$ was added $0.1 \mathrm{M} \mathrm{NaOH}(0.1 \mathrm{~mL})$. This mixture was shaken for $5 \mathrm{~min}$ and spun down at 5,500 rpm for $15 \mathrm{~min}$. The supernatant was carefully removed, and the pellet was rinsed with acetonitrile $(1 \mathrm{~mL})$ by centrifugation. This pellet was dispersed in methanol $(0.5 \mathrm{~mL})$ and mixed with the remaining solution $(0.98 \mathrm{~mL})$ of 4 TNB(Dox)(4-NP) prepared above. The mixture was sonicated for $30 \mathrm{~s}$ and shaken at room temp for $24 \mathrm{~h}$ in the dark. After reaction, the mixture was spun at 5,500 rpm for $15 \mathrm{~min}$. An aliquot of $0.02 \mathrm{~mL}$ was taken from the supernatant layer, diluted with PBS pH $7.4(1.0 \mathrm{~mL})$, and labeled as "aliquot 2". The remaining supernatant was carefully removed, and the pellet was rinsed three times with $50 \%$ acetonitrile/methanol (1.5 mL each) by centrifugation $(5,500 \mathrm{rpm}, 20 \mathrm{~min})$. The pellet was collected and dried under nitrogen atmosphere, affording UCN-PPIX@(Dox) as a pale red purple powder $(19.2 \mathrm{mg})$. The amount of TNB(Dox) covalently attached to the shell surface of UCN-PPIX was calculated as $0.892 \mathrm{mg}$ ( $44.6 \%$ conjugation yield) from the spectroscopic analysis of the two aliquots in which each aliquot was analyzed for its absorbance at $\lambda_{\max }$ (400 $\mathrm{nm})$ selected to quantify 4-nitrophenol (4-NP) generated. UV-vis $\left(1.0 \mathrm{mg} / \mathrm{mL}\right.$; methanol): $\lambda_{\max }=$ 445-512 nm (Dox), $408 \mathrm{~nm}$ (protoporphyrin IX), $255 \mathrm{~nm}$. 
12 UCN-PPIX@(Dox)(G5FA). First, G5(FA) ${ }_{6}$-a fifth generation (G5) PAMAM dendrimer conjugated with folic acid (average 6 FA per dendrimer nanoparticle; $\left.\mathrm{MW}=38,600 \mathrm{~g} \mathrm{~mol}^{-1}\right)^{4}$ was preactivated for conjugation with UCN-PPIX@(Dox). Thus, G5(FA)6 (3 mg, 77.7 nmol) was dissolved in DMF $(0.6 \mathrm{~mL})$ that contained NHS $(1.8 \mathrm{mg}, 15.5 \mu \mathrm{mol})$ and 4dimethylaminopyridine (DMAP; $1.9 \mathrm{mg}, 15.5 \mu \mathrm{mol})$. To this solution was added EDC (3.0 mg, $15.5 \mu \mathrm{mol})$ as a solid, and the mixture was stirred for $30 \mathrm{~min}$ at room temp. An aliquot (0.015 $\mathrm{ml})$ of the activated solution was taken out, diluted with PBS, pH $7.4(1.0 \mathrm{~mL})$, and labeled as "aliquot 3".

The solution $(0.585 \mathrm{~mL})$ of the preactivated $\mathrm{G} 5(\mathrm{FA})_{6}$ above was added to $\mathrm{UCN}$ PPIX@(Dox) (12 mg) in an Eppendorf vial. The mixture was shaken at room temp for 48 in the dark, and centrifuged at 5,500 rpm for $20 \mathrm{~min}$. The pale pink supernatant solution was carefully removed, and an "aliquot 4 " $(0.015 \mathrm{~mL})$ was taken out from the supernatant, and mixed with PBS, pH $7.4(1.0 \mathrm{~mL})$ for UV-vis analysis. The pellet was suspended in methanol $(1.0 \mathrm{~mL})$ and sonicated for $10 \mathrm{sec}$ before centrifugation. This rinsing process was repeated with methanol, 50\% aqueous methanol, and methanol. The pellet (reddish brown) was collected, and dried under nitrogen atmosphere $(12.2 \mathrm{mg})$. The amount of $\mathrm{G} 5(\mathrm{FA})_{6}$ conjugated was calculated by spectrophotometric analysis (absorption at $275 \mathrm{~nm}$ for FA) between "aliquot 3" and "aliquot 4", each taken before and after the conjugation reaction. This analysis led to $12.3 \%$ of G5(FA) 6 attached which is equivalent to $3.1 \%$ (w/w) of dendrimer to UCN-PPIX@ (Dox)(G5FA). UV-vis $\left(1.0 \mathrm{mg} / \mathrm{mL} ;\right.$ methanol): $\lambda_{\max }=285,220 \mathrm{~nm}\left(\mathrm{G} 5(\mathrm{FA})_{6}\right)$.

Cy5-labeled UCN Conjugates (11, 12). To 12 UCN-PPIX@(Dox)(G5FA) (0.4mg) weighed in an Eppendorf vial was added $0.1 \mathrm{mg}$ of sulfo-cyanine5 NHS ester (Molecular Probes $\left.{ }^{\circledR}\right)$ dissolved in anhydrous DMF $(0.3 \mathrm{~mL})$ and followed by the addition of $N, N$ - 
diisopropyl $N$-ethylamine $(0.03 \mathrm{~mL})$. This mixture was shaken at room temp for $12 \mathrm{~h}$ in the dark. After the reaction, it was centrifuged at 5,500 rpm for $20 \mathrm{~min}$, and its supernatant solution was carefully removed. The remaining UCN pellet was rinsed multiple times with methanol (1.0 $\mathrm{mL}$ ), 50\% aqueous methanol, and then methanol. It was collected and dried under nitrogen, yielding Cy5-labeled 12 as a blue powder $(0.34 \mathrm{mg})$. UV-vis spectroscopy: $\lambda_{\max }=670 \mathrm{~nm}$ (methanol). Cy5-labeled 11 UCN-PPIX@(Dox) was prepared in the same manner. 
4. Table S1. Summary of molecular properties and valency of 9 G5(FA $)_{n=5.4}(\text { Dox })_{m=5.1}$

\begin{tabular}{|c|c|c|c|c|}
\hline \multirow{2}{*}{$\begin{array}{l}\text { Dendrimer } \\
\text { Conjugate }\end{array}$} & \multirow[t]{2}{*}{$M_{\mathrm{r}}\left(\mathrm{g} \mathrm{mol}^{-1}\right)^{a}$} & \multirow[t]{2}{*}{$\mathrm{UV}-\mathrm{vis}\left(\lambda_{\max }, \mathrm{nm}\right)$} & \multicolumn{2}{|c|}{ Valency $^{c}$} \\
\hline & & & NMR & UV-vis \\
\hline $\mathrm{G} 5\left(\mathrm{NH}_{2}\right)_{114}$ & $27,600\left(1.09^{b}\right)$ & & - & - \\
\hline $8 \mathrm{G} 5(\mathrm{GA})_{n=108}$ & 40,200 & & $n=108^{3}$ & - \\
\hline $9 \mathrm{G} 5(\mathrm{FA})_{n}(\mathrm{Dox})_{m}$ & 47,400 & $\begin{array}{l}283,355(\mathrm{FA}) ; 480 \\
\text { (Dox) }\end{array}$ & $n=5.4( \pm 1.3)$ & $m=5.1( \pm 0.3)$ \\
\hline
\end{tabular}

${ }^{a}$ molecular weight of peak maxima (MALDI-TOF MS), $\mathrm{g} \mathrm{mol}^{-1} ;{ }^{b}$ polydispersity index $(\mathrm{PDI})=$ $M_{\mathrm{w}} / M_{\mathrm{n}}(\mathrm{GPC}) ;{ }^{c}$ mean $( \pm \mathrm{SD})$ 


\section{Figure S1, S2}

(A)

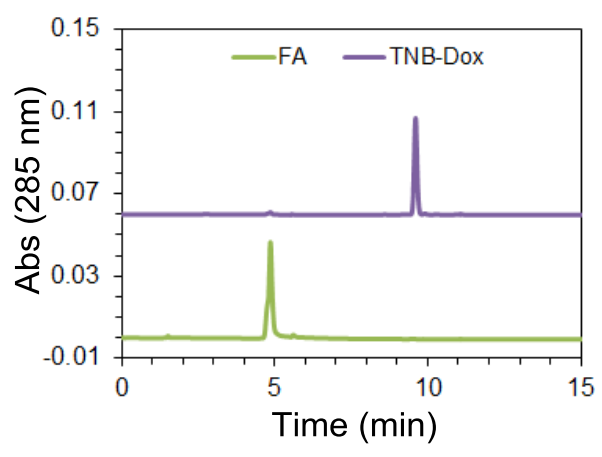

(C)

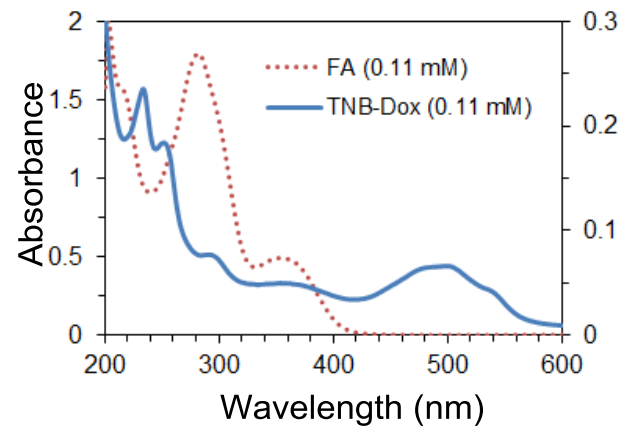

$(\mathrm{E})$

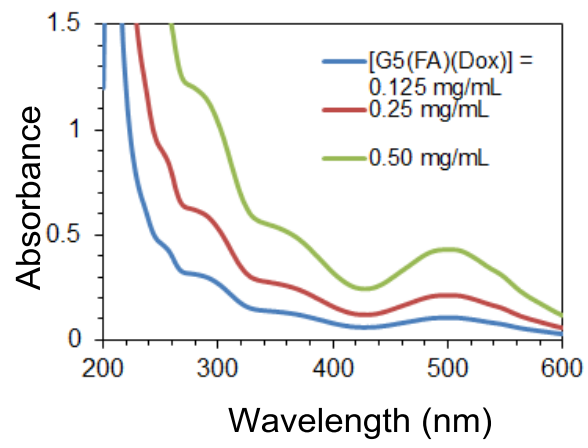

(B)

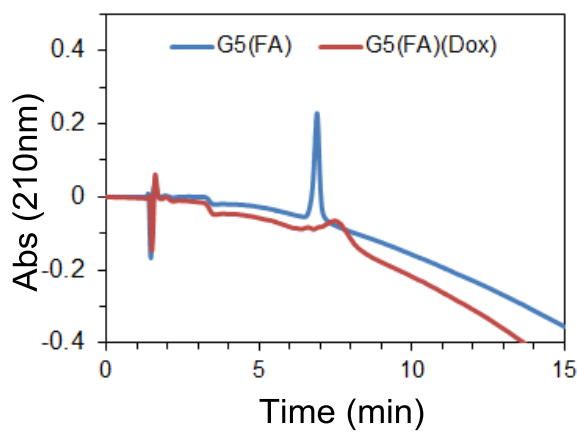

(D)

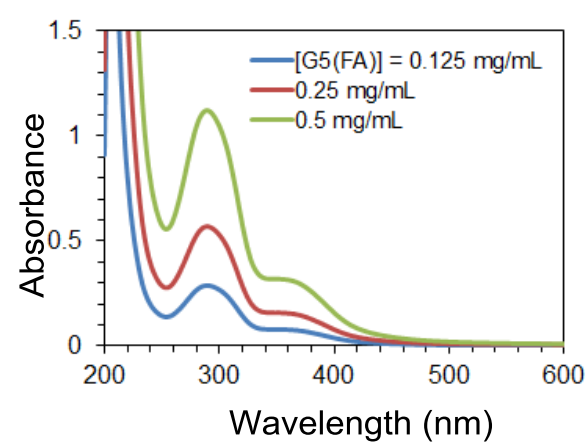

Figure S1. UPLC traces of folic acid (FA) and 5 TNB(Dox)(NHBoc) (A), and dendrimer conjugates G5(FA)6, 9 G5(FA) $5.4(\text { Dox })_{5.1}(\mathrm{~B})$; UV-vis spectra of FA and 5 TNB(Dox)(NHBoc) (C), G5(FA) 6 (D) and 9 G5(FA) $)_{5.4}(\text { Dox })_{5.1}(\mathrm{E})$. For UV-vis spectrometry, each conjugate was measured in PBS pH 7.4. 


$$
\text { mean }=5.4(n), 5.1(m)
$$

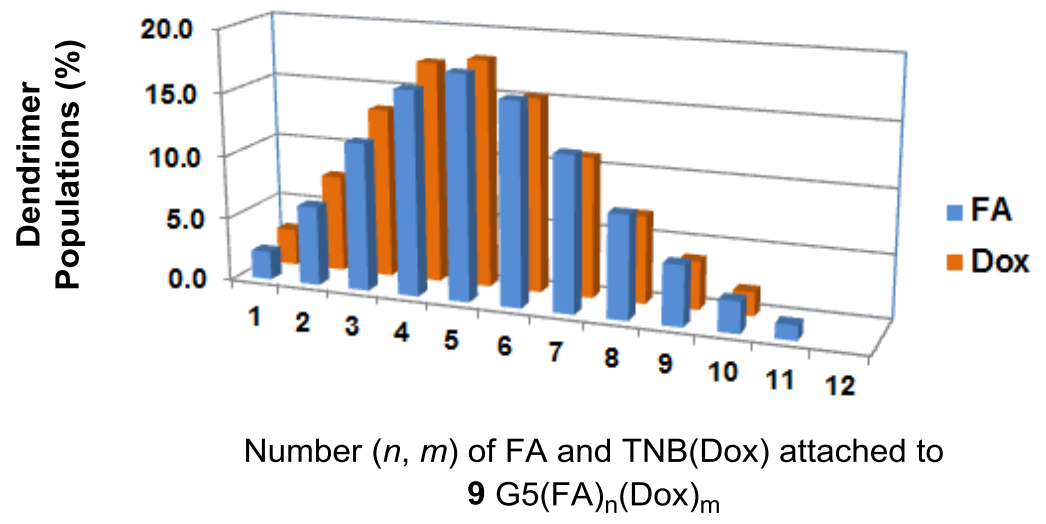

Figure S2. Poissonian distribution of dendrimer species with regards to the valency of FA and Dox in 9 G5(FA) $(\text { Dox })_{\mathrm{m}}$ with the mean value of $n=5.4$ (FA) and $m=5.1$ (Dox). Dendrimer species with variable valency $(n, m)$ are plotted as $\%$ fractional populations. 


\section{Copies of Spectral Data for 3, 4, 5, and 9}

(A) ${ }^{1} \mathrm{H}$ NMR spectrum of $3\left(500 \mathrm{MHz} ; \mathrm{CDCl}_{3}\right)$
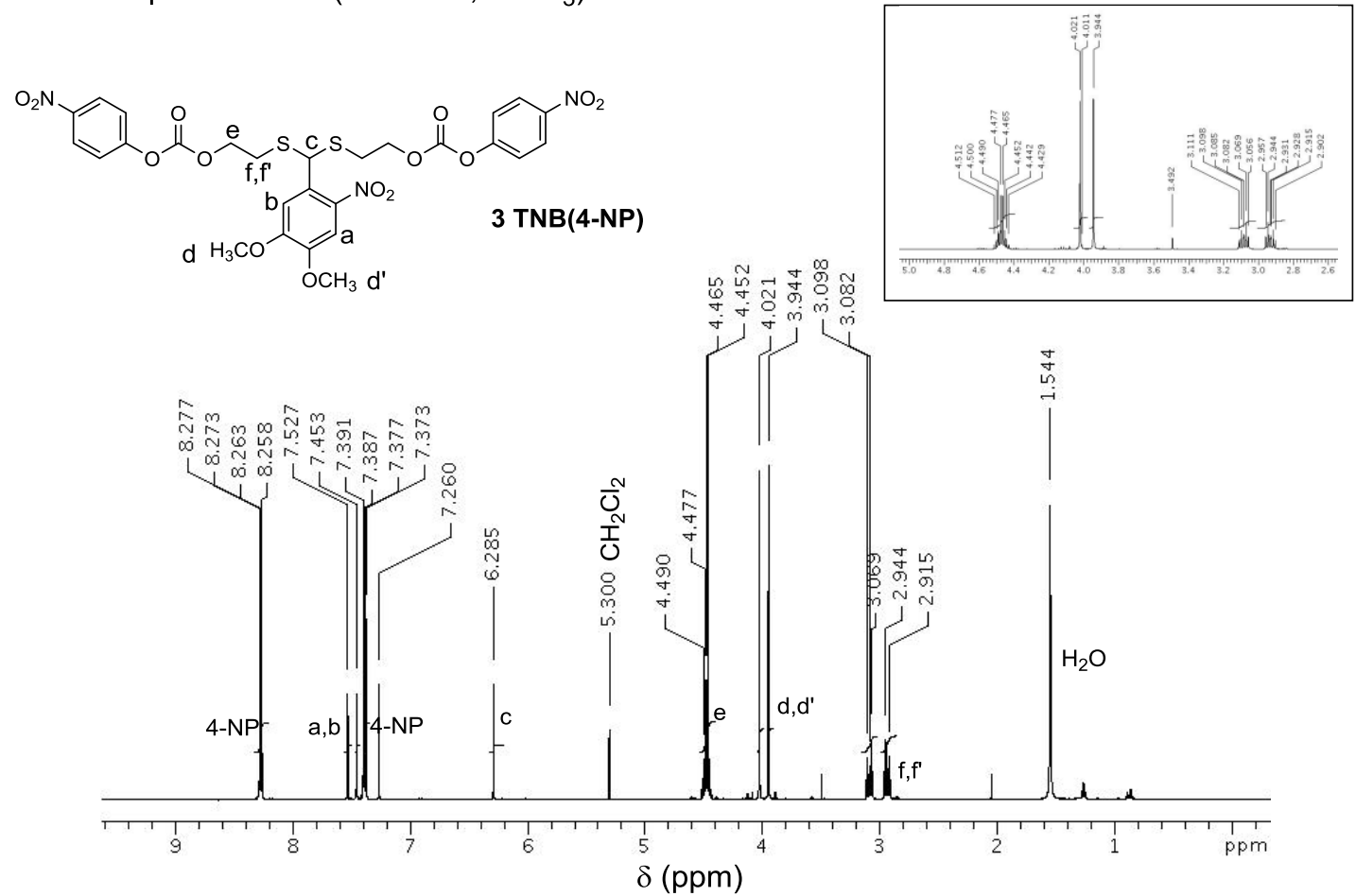

(B) ESI mass spectrum of 3

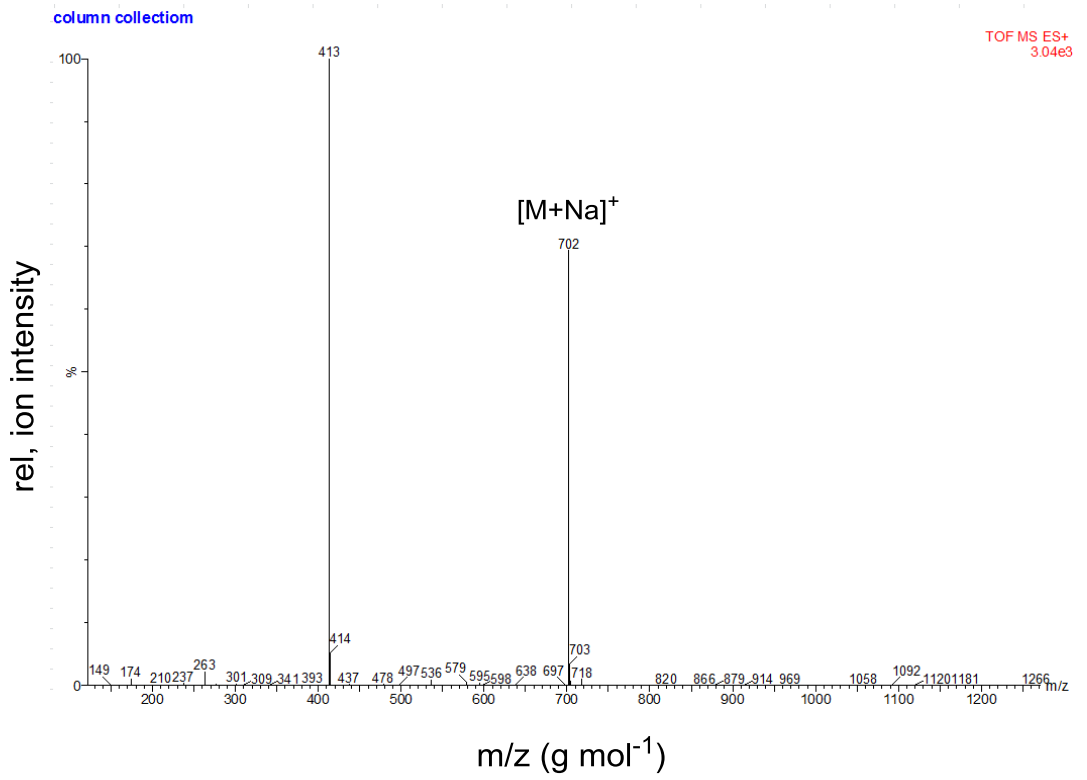


(A) ${ }^{1} \mathrm{H}$ NMR spectrum of $4\left(500 \mathrm{MHz} ; \mathrm{CDCl}_{3}\right)$

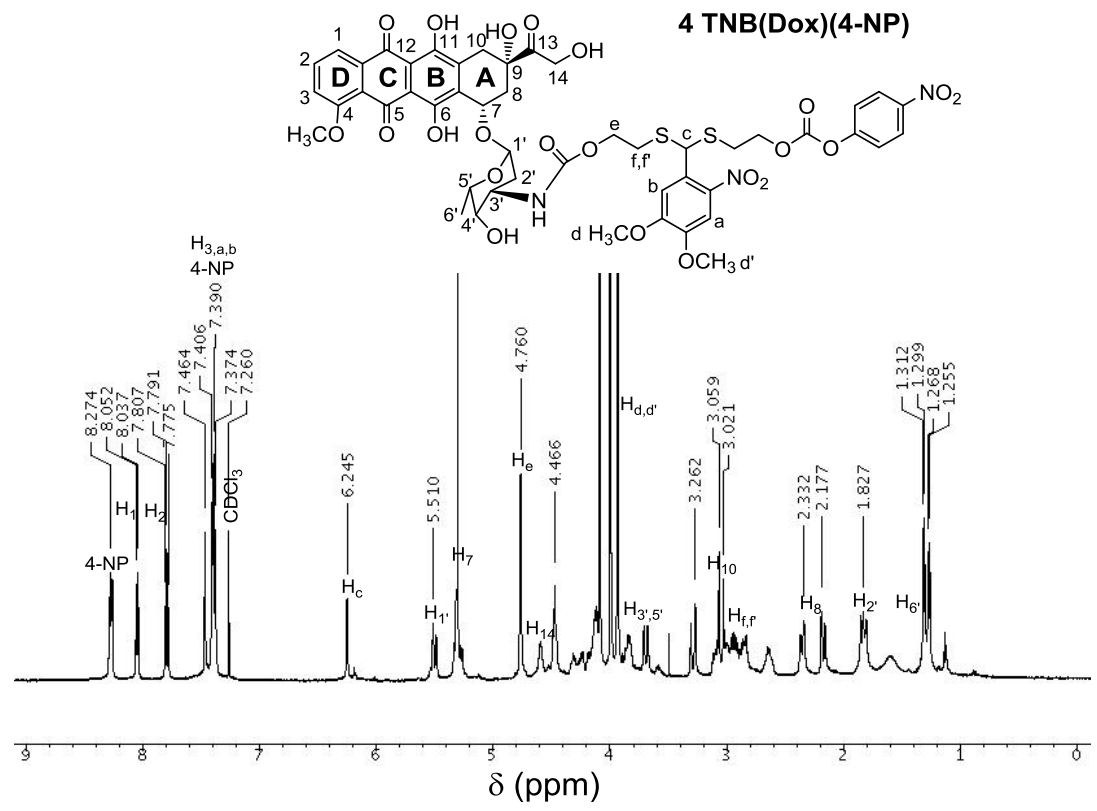

(B) ${ }^{13} \mathrm{C}$ NMR spectrum of $4\left(100 \mathrm{MHz} ; \mathrm{CDCl}_{3}\right)$
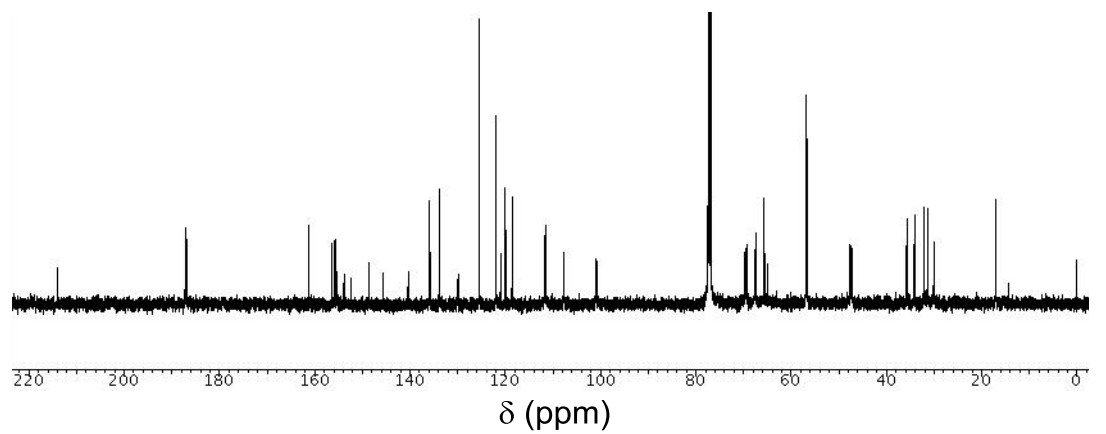

(C) HRMS mass spectrum of 4

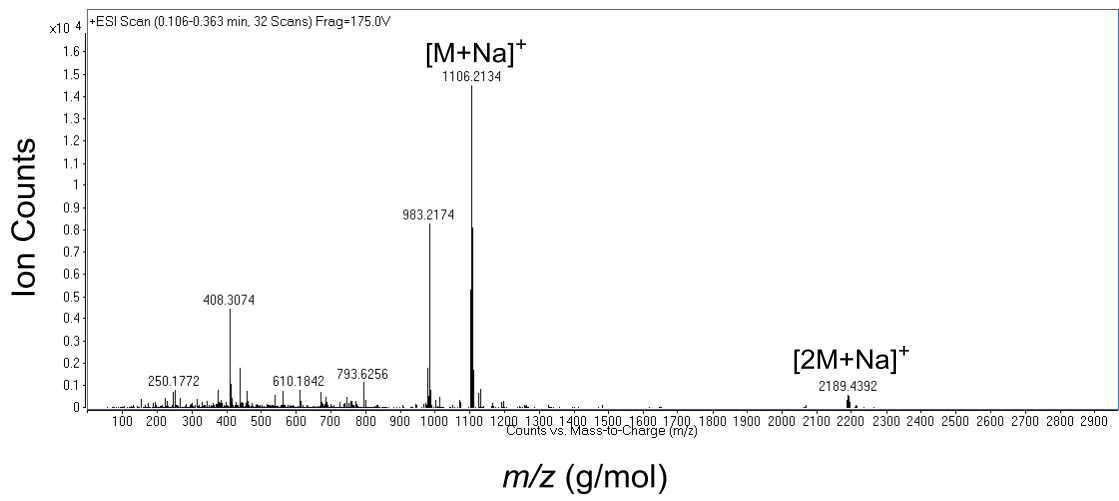


(A) ${ }^{1} \mathrm{H}$ NMR spectrum of $5\left(500 \mathrm{MHz} ; \mathrm{CDCl}_{3}\right)$

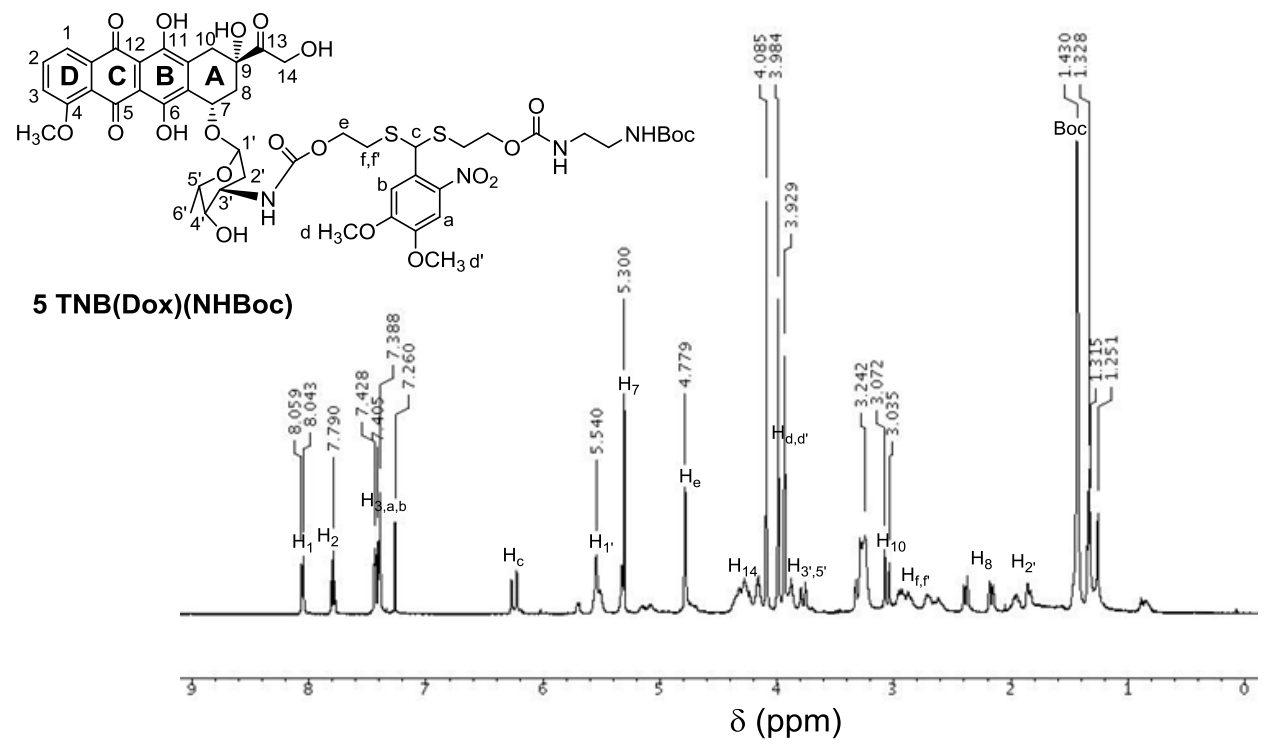

(B) ${ }^{13} \mathrm{C}$ NMR spectrum of $5\left(500 \mathrm{MHz} ; \mathrm{CDCl}_{3}\right)$

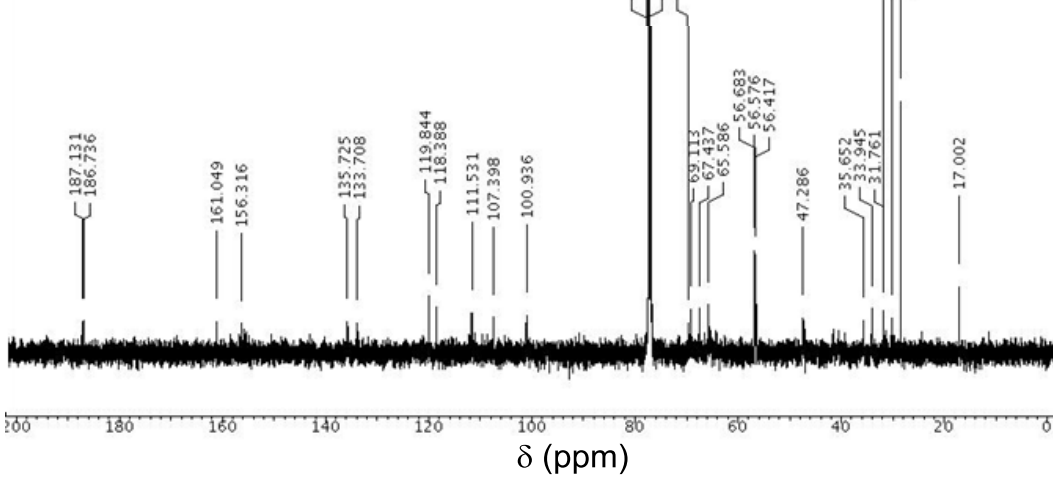

(C) HRMS mass spectrum of 5

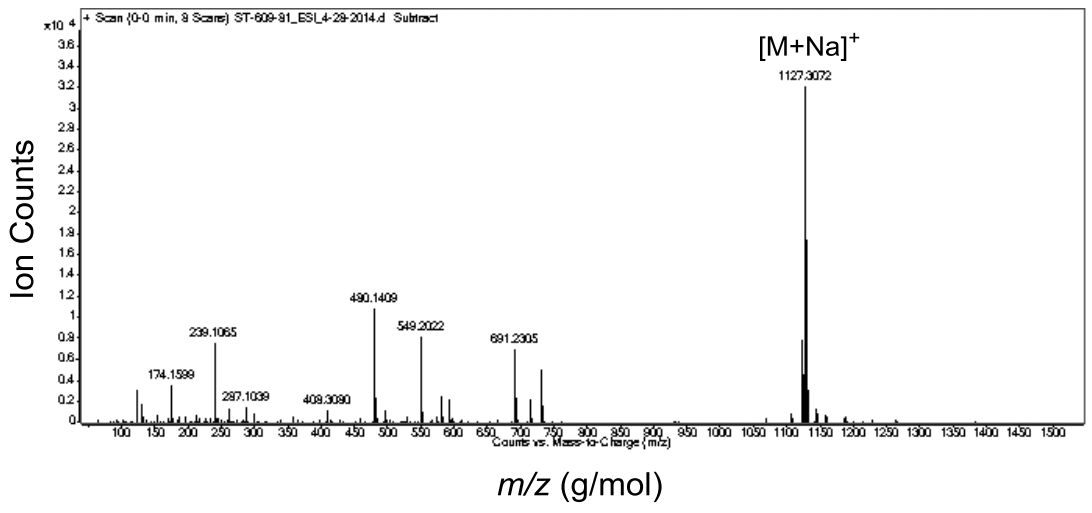


(A) ${ }^{1} \mathrm{H}$ NMR spectrum of 9 (500 MHz; DMSO- $d_{6}$ )

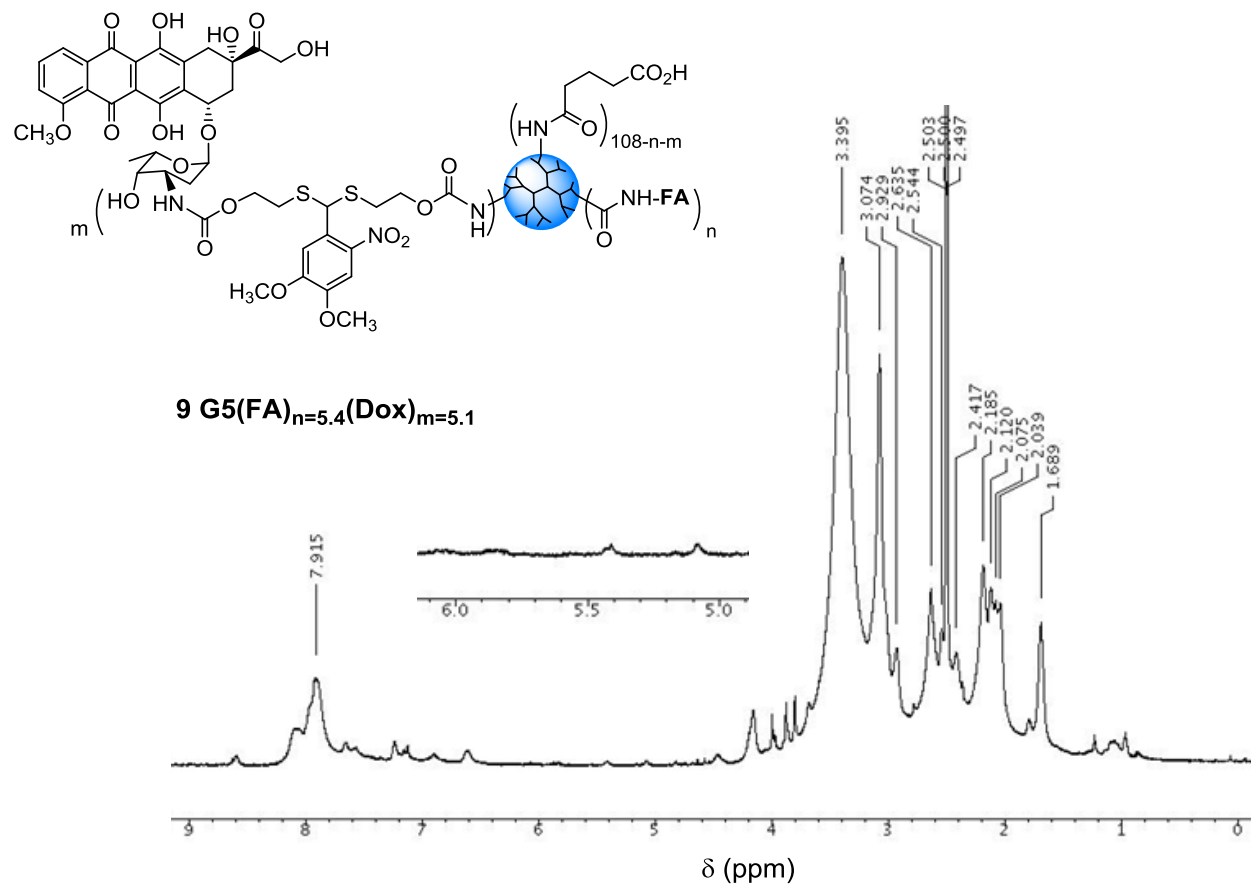

(B) MALDI mass spectrum of 9

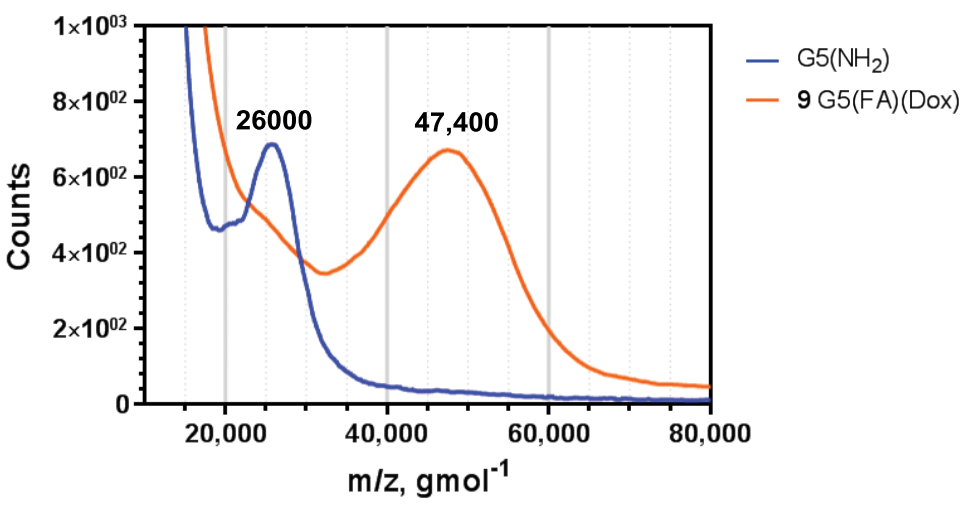




\section{References}

1. Majoros, I. J.; Thomas, T. P.; Mehta, C. B.; Baker Jr, J. R. Poly(amidoamine) DendrimerBased Multifunctional Engineered Nanodevice for Cancer Therapy. J. Med. Chem. 2005, 48, 5892-5899.

2. Wong, P. T.; Tang, S.; Cannon, J.; Mukherjee, J.; Isham, D.; Gam, K.; Payne, M.; Yanik, S. A.; Baker, J. R.; Choi, S. K. A Thioacetal Photocage Designed for Dual Release: Application in the Quantitation of Therapeutic Release by Synchronous Reporter Decaging. ChemBioChem 2017, 18, 126-135.

3. Choi, S. K.; Thomas, T.; Li, M.; Kotlyar, A.; Desai, A.; Baker Jr, J. R. Light-Controlled Release of Caged Doxorubicin from Folate Receptor-Targeting PAMAM Dendrimer Nanoconjugate. Chem. Commun. (Cambridge, U. K.) 2010, 46, 2632-2634.

4. Wong, P. T.; Chen, D.; Tang, S.; Yanik, S.; Payne, M.; Mukherjee, J.; Coulter, A.; Tang, K.; Tao, K.; Sun, K.; Baker Jr, J. R.; Choi, S. K. Modular Integration of Upconversion Nanocrystal-Dendrimer Composites for Folate Receptor-Specific Near Infrared Imaging and Light Triggered Drug Release. Small 2015, 11, 6078-6090.

5. Tian, Q.; Tao, K.; Li, W.; Sun, K. Hot-Injection Approach for Two-Stage Formed Hexagonal NaYF4:Yb,Er Nanocrystals. J. Phys. Chem. C 2011, 115, 22886-22892.

6. $\quad$ Chen, D.; Tao, R.; Tao, K.; Chen, B.; Choi, S. K.; Tian, Q.; Xu, Y.; Zhou, G.; Sun, K. Efficacy Dependence of Photodynamic Therapy Mediated by Upconversion Nanoparticles: Subcellular Positioning and Irradiation Productivity. Small 2017, 13, 1602053. 